\title{
En la frontera: tensiones políticas y económicas de la ganadería bovina en el norte de Coahuila, $1947-1982$
}

\section{On the Border: Political and Economic Tensions of the Cattle Industry in Northern Coahuila, 1947-1982}

\author{
Reynaldo de los Reyes \\ El Colegio de México; Ciudad de México, México \\ email: reynaldo.reyesp@gmail.com
}

Resumen. El objetivo de este artículo es analizar cómo a mediados del siglo Xx las políticas nacionales mexicanas y estadunidenses alteraron la dinámica regional transfronteriza de la ganadería del norte de Coahuila. El estudio se centra en las tensiones políticas y económicas generadas por el cierre de la frontera a raíz de la crisis sanitaria de 1947, para explicar que el repliegue territorial de la ganadería coahuilense, en un contexto ambiental poco favorable, produjo las condiciones que frenaron su dinamismo en los siguientes años. El artículo cierra alrededor de 1982, cuando el Estado mexicano comenzó a disminuir las regulaciones económicas que dieron pie a políticas de libre comercio.

Palabras clave: historia transnacional; frontera México-Estados Unidos; ganadería.

Abstract. The main goal of this paper is to analyze how, in the middle of the 20th century, Mexican and US national policies altered the regional cross-border dynamics of cattle ranching in northern Coahuila. The study focuses on political and economic tensions generated by the closing of the border in the wake of the 1947 sanitary crisis, to explain that the territorial withdrawal of the Coahuila cattle ranching, in an unfavorable environmental context, produced the conditions that stopped its dynamism in the following years. The paper closes around 1982, when the Mexican state began to decrease the economic regulations that gave rise to free trade policies.

Key words: transnational history; Mexico-United States borderlands; cattle industry.

JEL: Q11; Q18; N56.

Fecha de recepción: 14 de julio de 2017. Fecha de aceptación: 12 de diciembre de 2017.

Financiamiento: esta investigación contó con el apoyo del Instituto de Investigaciones Dr. José María Luis Mora, así como del Consejo Nacional de Ciencia y Tecnología (México), a través de su programa de becas y del proyecto 220138, Espacios 
Económicos, Dinámicas Empresariales y Desarrollo Regional en el Norte de México. De la Política Sustitutiva de Importaciones a los Mercados Globalizados (1945-1994). Agradezco el apoyo de todos ellos, así como el de los evaluadores anónimos.

\section{INTRODUCCIÓN}

A border is a dividing line, a narrow strip along a steep edge. A borderland is a vague and undetermined place created by the emotional residue of an unnatural boundary. It is in a constant state of transition. The prohibited and forbidden are its inhabitants.

Anzaldúa (1987, p. 21).

$\mathrm{L}$ ejos de separar a las naciones, las líneas divisorias internacionales se convierten en sus más decididos puntos de encuentro. La frontera como línea conjuga los procesos que se dan en los espacios fronterizos y tiende a consolidarlos como territorios de constante transición, donde sus habitantes, como dice Gloria Anzaldúa, son lo prohibido. Son lo prohibido porque viven en un espacio permeable, donde capitalizan los peligros y oportunidades de vivir lejos de los centros de poder. En este sentido, sus dinámicas representan un potencial riesgo para sus respectivos Estados nacionales.

El objetivo de este artículo es reconstruir las dinámicas económicas de la ganadería bovina del norte de Coahuila, inserta en un espacio transfronterizo del noreste de México y el estado de Texas. Aunque privilegio el enfoque regional, lo que pretendo hacer es una lectura transnacional del fenómeno económico que explique las tensiones entre el mercado nacional y el internacional. ${ }^{1}$ Desde finales del siglo XIX, esta ganadería se insertó en el mercado mundial de carne a través de la llegada de ganaderos estadunidenses y de la exportación de ganado en pie para ser engordado al norte del Bravo. Intentaré demostrar que, a partir de 1947, como producto de una crisis sanitaria que detuvo los intercambios entre ambos países, se dio un repliegue parcial de la ganadería norcoahuilense que, en condiciones de fragilidad ambiental, frenó su dinamismo en las siguientes décadas. Este repliegue parcial, por el que entiendo la disminución de la movilidad territorial del ganado, fue producto de regulaciones políticas de distintos órdenes de gobierno y afectó tanto a productores como a consumidores.

\footnotetext{
${ }^{1}$ Como lo enuncian recientemente Lopes y Zuleta (2016), "el enfoque histórico regional alcanza dimensiones transnacionales [...] cuando las economías regionales son examinadas como resultado de procesos y dinámicas de interconexión transfronterizas” (pp. 13-14).
} 
Mi marco de análisis es el de la frontera como un espacio difuso, donde las dinámicas económicas y sociales desafían los límites de la política del Estado nación. Los procesos que hicieron de la ganadería del norte de México una actividad transnacional de este tipo datan al menos de la modificación de la línea fronteriza producida por la invasión estadunidense de 1846-1847. Como apunta Cerutti y González (1993), después de este evento se comenzó a construir un "espacio económico común en torno al Bravo, un espacio regional binacional que habría de reforzarse en décadas posteriores, [donde] los agentes sociales portadores del capital -núcleos burgueses en pleno crecimiento- volcaron su racionalidad ante las oportunidades que ofrecía este auténtico territorio de frontera" (p. 10). Durante la guerra de secesión estadunidense (1861-1865) la actividad económica fundamental fue el comercio, incentivado por el carácter limítrofe del Bravo, pero durante los años de la reconstrucción surgieron también la agricultura, la ganadería y, poco más tarde, la minería.

Esta frontera, sin embargo, siguió siendo difusa. Según Friedrich Katz (1998, pp. 23-24), antes de la llegada de Porfirio Díaz al poder, los estados de Sonora, Chihuahua y Coahuila "gozaban de una existencia prácticamente autónoma. Remotos y aislados, no solamente del resto de la república sino del resto del mundo, virtualmente independientes en lo político y autosuficientes en lo económico, eran la columna vertebral de la 'frontera' norte de México". Posteriormente, de acuerdo con el mismo autor, con la llegada de Díaz y la expansión de los ferrocarriles, ocurrieron dos transformaciones, una política y otra económica: la primera consistió en la imposición del poder central mexicano sobre los caudillos regionales, y la segunda en un aumento de las inversiones estadunidenses. Lo anterior dio pie a la transición de una frontera con los indios nómadas a una frontera con Estados Unidos (frontier to border), que en términos prácticos significaba la integración política a México y el estrechamiento de las relaciones económicas con el vecino del norte. Como afirma Mora-Torres (2001), este proceso dual de centralización política y modernización capitalista dotó al norte mexicano de un carácter peculiar, dada su posición como zona de contacto entre dos naciones (pp. 5-6).

El norte de México, entonces, se volvió un espacio de disputa territorial donde los respectivos Estados nación buscaron afianzar sus dominios, sea a través de proyectos políticos o económicos. Una de las formas de hacerlo fue impulsando proyectos de desarrollo económico regional, estructurados sobre la base de las economías preexistentes, mismos que no se formaron en el vacío ni fueron simplemente impuestos por el gobierno y el capital estadunidense, como ha explicado Casey Walsh (2008). Más bien, estos proyectos fueron una respuesta y adaptación a las condiciones sociales y ambientales particulares, donde las fuerzas globales y nacionales 
interactuaron con las fuerzas regionales para dar a la sociedad y cultura fronteriza su forma y actitud particular, como lo ha explicado este autor a partir del proyecto algodonero (pp. 6-7).

Para Aboites (2013), esta misma experiencia con el algodón "es prueba fehaciente de que el norte mexicano contemporáneo, el que se formó a partir de 1870, tiene como motor, por un lado, la conexión simultánea con el centro del país, con la ciudad de México, con el gobierno federal, con la industrial textil y con los trabajadores migrantes y, por otro, con la economía, los empresarios y con las autoridades gubernamentales estadunidenses" (p. 18). El algodón debe considerarse entonces como un nudo económico y político en el que se ven involucrados elementos de los dos países. Esta doble conexión, concluye Aboites, constituye no sólo la base de la experiencia algodonera, sino la historia general del norte mexicano en el siglo XX.

Aunque el algodón ha sido explorado de forma más amplia, no es sino recientemente que la historiografía ha estudiado la ganadería mexicana del siglo Xx. ${ }^{2}$ La actividad pecuaria, a diferencia del algodón, no requirió de muchos brazos ni de una amplia inversión estatal; el desarrollo de esta actividad como una empresa individual le permitió un desenvolvimiento más autónomo, pero que no estuvo exento de entrar en conflictos con los respectivos Estados-nación e incluso con autoridades locales.

Para explorar lo anterior, he dividido el artículo en cuatro apartados. En el primero, expondré cómo se dio la integración comercial y territorial de la ganadería del norte de Coahuila al mercado estadunidense; en el segundo, analizaré las dificultades del sector ante el cierre de fronteras y las condiciones desfavorables del mercado estadunidense; en el tercero, me ocuparé de las complicaciones de atender el mercado interno, y finalmente, daré seguimiento de la evolución ganadera de la región hasta inicios de la década de 1980, cuando se muestra un marcado declive de la actividad pecuaria.

\section{LA GANADERÍA: UNA ECONOMÍA DESBORDADA}

Durante el siglo XIX la hegemonía del mercado mundial de carne perteneció a los británicos. El proceso de revolución industrial y la migración del campo a la ciudad los llevaron a importar este insumo de otras partes

${ }^{2}$ Los trabajos al respecto son escasos, aunque de calidad notable. El más completo es el de Machado (1981), que abarca el periodo 1910-1975; le sigue en cronología Camou (1998), quien se ocupa de Sonora en la segunda mitad del siglo Xx, y recientemente los artículos de Lopes (2003, 2008, 2016, 2017) y Lopes y Riguzzi (2012), que van desde la escala local (Sonora y Chihuahua) hasta la subcontinental (América del Norte). 
de Europa y de Estados Unidos, que había tenido un auge ganadero importante a lo largo del siglo. A principios del xx la situación empezó a cambiar. La expansión agrícola estadunidense comenzó a limitar su cabaña ganadera y el país tuvo que disminuir sus exportaciones, a la par que Argentina y Uruguay se convirtieron en los nuevos abastecedores de los británicos, quienes dominaban la industrialización de carne en estos países sudamericanos. Mientras que Gran Bretaña buscaba el control del proceso ganadero fuera de la isla, Estados Unidos no tardó en transformar el sistema ganadero dentro de su inmenso territorio. Su principal aportación se debió a que revolucionaron el cultivo de cereales y lo transformaron en el insumo esencial de una nueva forma de producción. Así convirtieron a la ganadería pastoril en una de engorda industrial o de corral (Pérez, 1991, pp. 443-447).

Esta nueva forma de producción llevó a la especialización de zonas ganaderas. El medio oeste de Estados Unidos, debido a su gran disponibilidad de granos, engordaba el ganado que se criaba y preengordaba en el suroeste de ese país. Este proceso, naturalmente, arrastró a algunas de sus economías subsidiarias como era el caso de Canadá y México. Las inversiones británicas fueron parte importante de esta expansión, que tuvo su auge entre 1880 y 1885; dichas inversiones no se limitaron al suroeste estadunidense, sino que se extendieron a Australia y en menor medida a México.

El norte de Coahuila no fue la excepción de este flujo de capitales, y en la década de 1880 el auge de las inversiones extranjeras arribó a la entidad. En 1881, por ejemplo, se formó al norte del Bravo la Texas Land and Cattle Company para adquirir cuatro haciendas en el territorio mexicano (Graham, 1960, p. 429), y ese mismo año, un empresario escocés adquirió propiedades para colonizar tierras en Nuevo México, Durango y Coahuila. Este último vio frustrados sus intereses dada la crisis de esa década, que no le permitió conseguir inversionistas ni el financiamiento del British and Australian Trust Company; ello, sin embargo, no significó el cese de las oportunidades de negocio, y diez años después la familia McKellar decidió establecerse en su hacienda coahuilense de 100000 hectáreas (McKellar, 1994, pp. 13-15). A ella se sumaron algunos texanos, como Moore, Lytle, Blocker y Jennings, quienes en conjunto adquirieron en 1899 el rancho Piedra Blanca, en Coahuila, con poco más de 200000 hectáreas, y Coleman, uno de los ganaderos más importantes de Texas, quien pagó 3500000 dólares por el famoso rancho Milmo, en los límites de Nuevo León y Coahuila, compuesto por más de 400000 hectáreas (History of the cattlemen, 1991, pp. 93, 149-150, 284). Estas adquisiciones, ejemplo de otras importantes a lo largo de la frontera, y aunadas a las grandes posesiones de terratenientes mexicanos, representaron el desbordamiento territorial 
de la economía ganadera estadunidense e integraron el norte mexicano al mercado de carne noratlántico (Lopes, 2016).

¿Por qué el campo mexicano resultaba atractivo? Por un lado, se debió a la llegada del ferrocarril y a las políticas porfirianas, que brindaron el marco idóneo para un amplio mercado de tierras a precios bajos, tanto para extranjeros como para mexicanos. Este último punto es de especial relevancia dado el aumento en los precios de las tierras texanas, producto de la expansión algodonera. Tras el crecimiento exponencial que tuvo en Estados Unidos la actividad pecuaria durante la segunda mitad del siglo XIX, esta tendió a disminuir a partir de 1890 y lo seguiría haciendo hasta 1930. Ni siquiera la demanda que significó la gran guerra en Europa pudo revitalizarla: mientras la cabaña bovina estadunidense creció $23 \%$ entre 1900 y 1910, la texana se mantuvo estable (véase gráfica 1). La expansión agrícola de Estados Unidos limitó, parcialmente, el crecimiento de su ganadería, sobre todo en Texas. Un dato nos ayuda a indicarlo: entre 1879 y 1929, la superficie cosechada de algodón en Texas pasó de 2000000 a 16000000 de acres, lo que es casi el tamaño de Irlanda (véase gráfica 2). Con un espacio limitado, los ganaderos texanos tuvieron que modernizar sus sistemas de explotación, buscar tierras en México o comprar cada vez más ganado procedente del sur del Bravo (Lopes, 2003, 2016).

Es a partir de la década de 1930 cuando se puede observar de nuevo un crecimiento en el hato bovino de Texas. Debido a la Gran Depresión, el gobierno federal tomó medidas para recortar la superficie agrícola en Estados Unidos con el objetivo de disminuir la producción y recuperar los precios, que habían caído drásticamente. El algodón, que venía ya presenciando un declive, disminuyó así su superficie cosechada de 16000000 de acres en 1929 a sólo 6000000 en 1944. Es bastante probable que esto haya contribuido, desde la década de 1930, a una expansión de la ganadería bovina en Texas.

Pero cuando el crecimiento desmedido del hato se combinaba con una eventual caída de precios, los ganaderos texanos enfrentaban graves problemas, ya que retener el ganado por mucho tiempo esperando un repunte de precios podía agotar los pastizales y erosionar los suelos. En este punto el norte de México significaba una solución al menos provisional. Sus tierras áridas funcionaban como albergue de una población flotante de bovinos que cruzaba la frontera para aprovechar los pastos al sur del Bravo. Los estadunidenses compraron o arrendaron tierras para tratar de controlar su producción en estos frágiles ecosistemas que resentían cada vez más la sobrepoblación de herbívoros.

El norte de México, sin embargo, no era precisamente la cornucopia: era un territorio árido o semiárido con escasas precipitaciones, donde las sequías fueron frecuentes y donde también se requirió de mucha movili- 


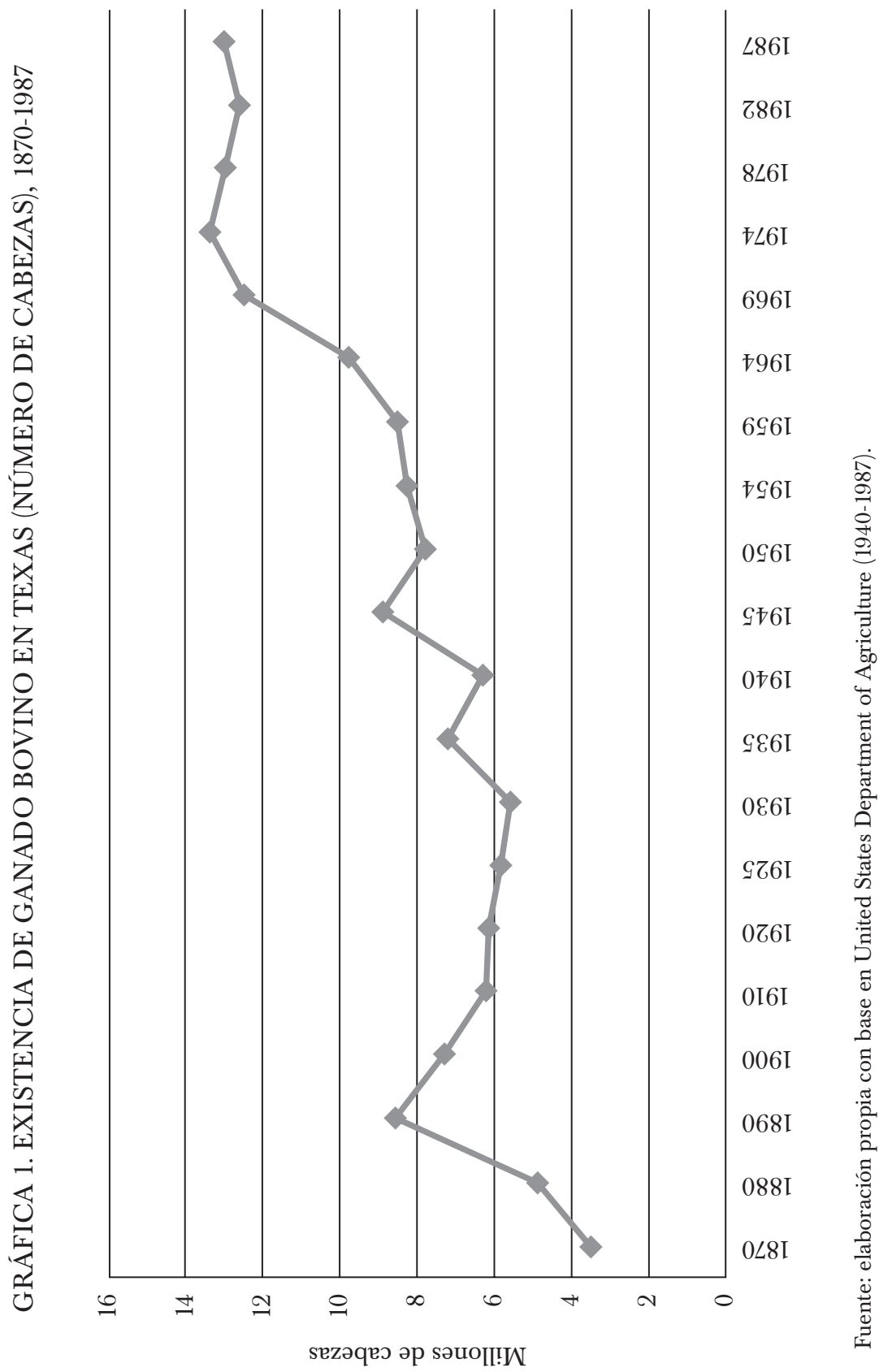



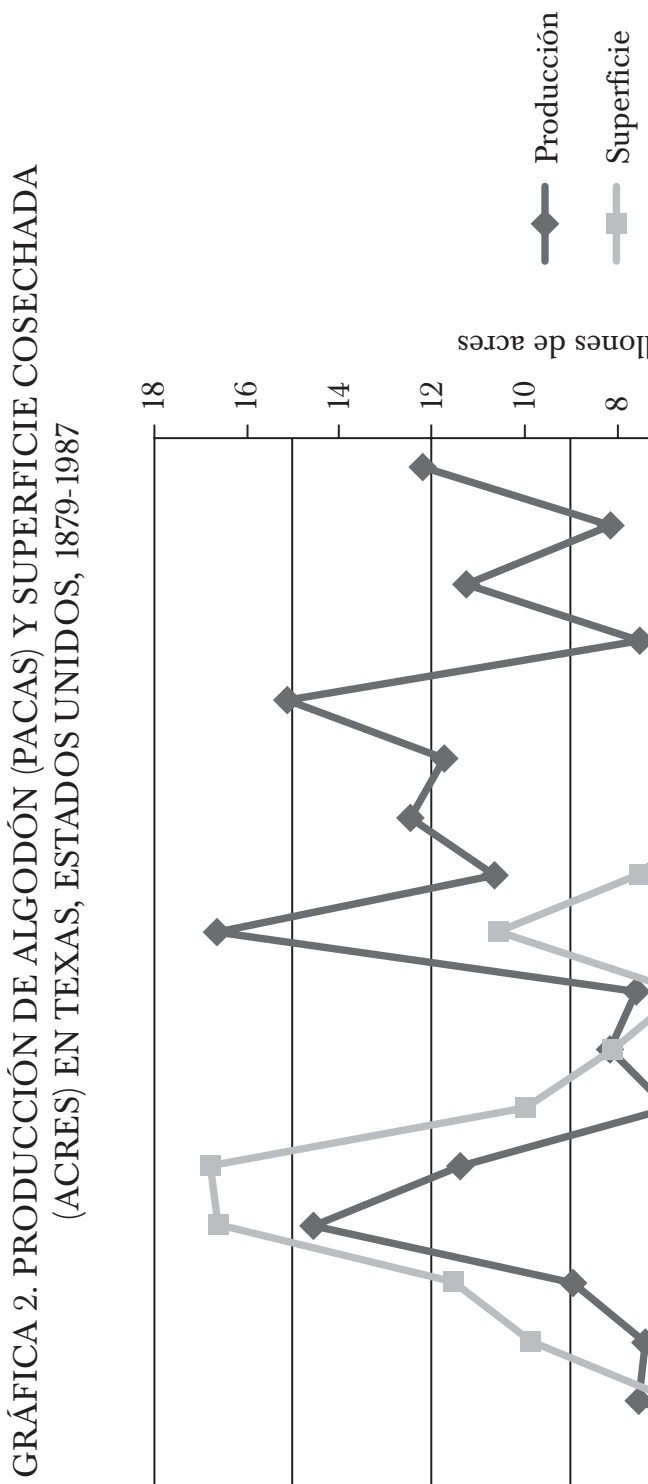

sәлวе әр sәuоाI!W
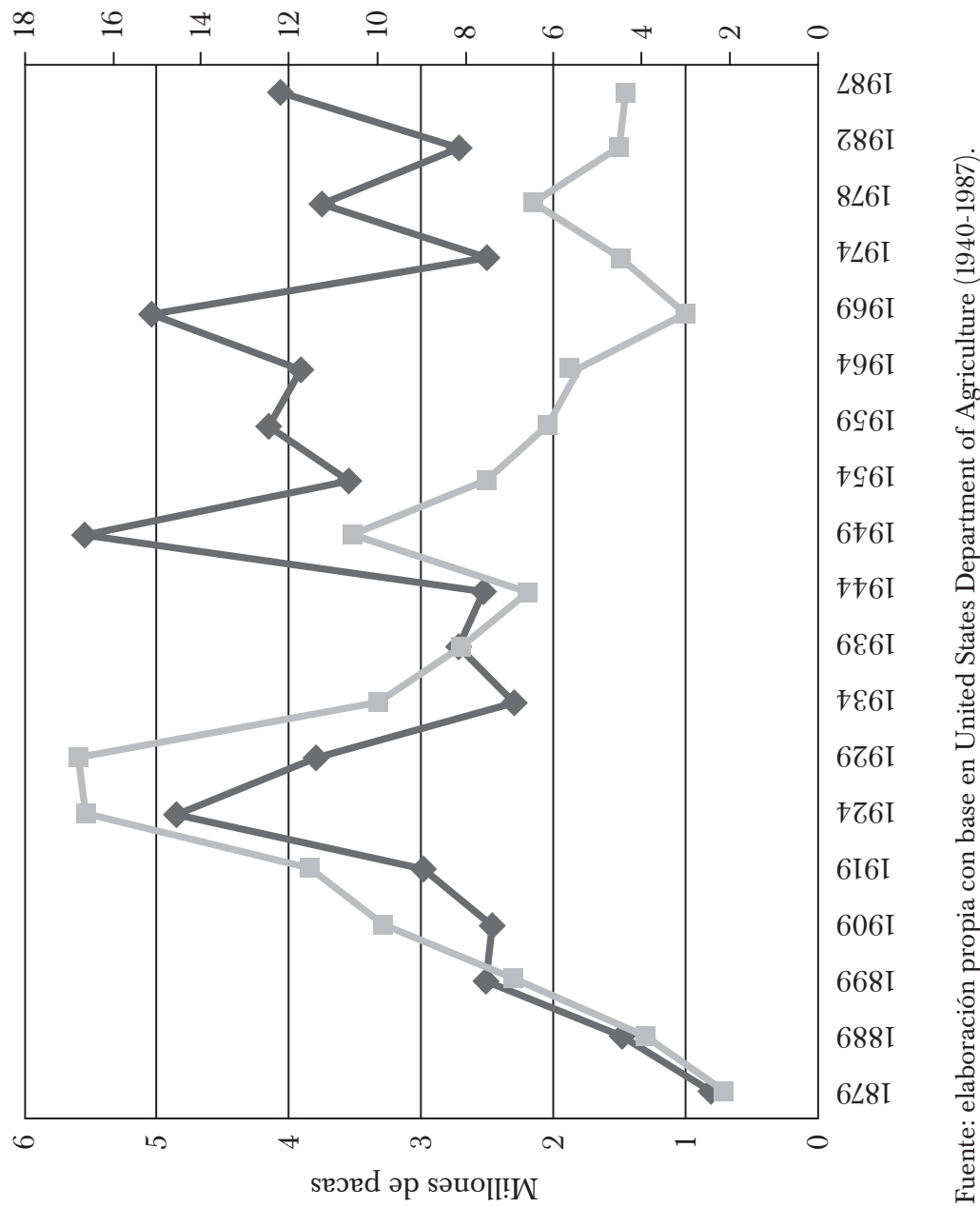
dad para los animales. La gráfica 3, formada con las precipitaciones anuales del rancho La Mariposa, en Múzquiz, Coahuila, muestra cómo entre 1907 y 1918 hubo once años con precipitaciones por debajo del promedio -siete de ellos de manera consecutiva. Entre 1926 y 1929 ocurrió el mismo fenómeno y -casualidad o no-, estos periodos coincidieron con momentos de grandes exportaciones. La sequía tuvo efectos en toda la región y, a decir de un ganadero texano que a la postre se establecería en México, a los rancheros estadunidenses se les permitió, sin pagar impuestos, llevar a sus vacas en verano y regresarlas en otoño acompañadas de sus becerros sin destetar. "Naturalmente, tenían 100\% de pariciones", agregó sarcásticamente (Ewing, 1995, p. 61).

Por todos estos factores, se configuró hacia la medianía del siglo XX una economía ganadera transnacional, donde la integración no fue sólo de intercambios comerciales sino de conexiones territoriales. En ella, un novillo nacido en México regularmente era criado hasta los diez o doce meses, cuando pesaba de 160 a 180 kilos; luego, era llevado a los estados fronterizos de Texas, Arizona y Nuevo México, donde empezaba su proceso de engorda hasta alcanzar unos 350 kilos, posteriormente era transportado a Oklahoma, Arkansas y Kansas, así como a partes cercanas de Colorado, Wyoming o Montana, donde aumentaba su peso hasta los 450 o 500 kilos, y finalmente, era sacrificado para su consumo (Bancos de Comercio, 1967, p. 32) (véase mapa 1).

La segunda guerra mundial catapultó a Estados Unidos para convertirlo en el principal productor y consumidor del orbe. Por la misma razón, México exportó durante esos años 500000 cabezas anuales de ganado bovino en pie para ser engordado al norte del Bravo. Se creó un sistema ganadero que soportaba miles de novillos, dándoles salida a una edad temprana, para que así sus pastos pudieran recuperarse para el siguiente año y repetir el ciclo. Pero una contingencia sanitaria, en 1947, interrumpió repentinamente este sistema.

\section{HoLDING THE LINE. SOBREVIVIR AL MURO EN EL NORTE DE COAHUILA, 1947-1954}

Los años cuarenta habían sido una época de intensa recuperación ganadera. En el norte de Coahuila (véase mapa 2) el hato había pasado de 162000 a 306000 cabezas, un incremento de 89\%. Una tercera parte de ese ganado era considerada ganado fino. Pero con la Navidad de 1946 llegó una mala noticia para el campo mexicano. El 26 de diciembre de ese año, se anunció un brote de fiebre aftosa en Veracruz que pronto se extendería a buena parte del país. Este brote fue atribuido a un lote de ganado 

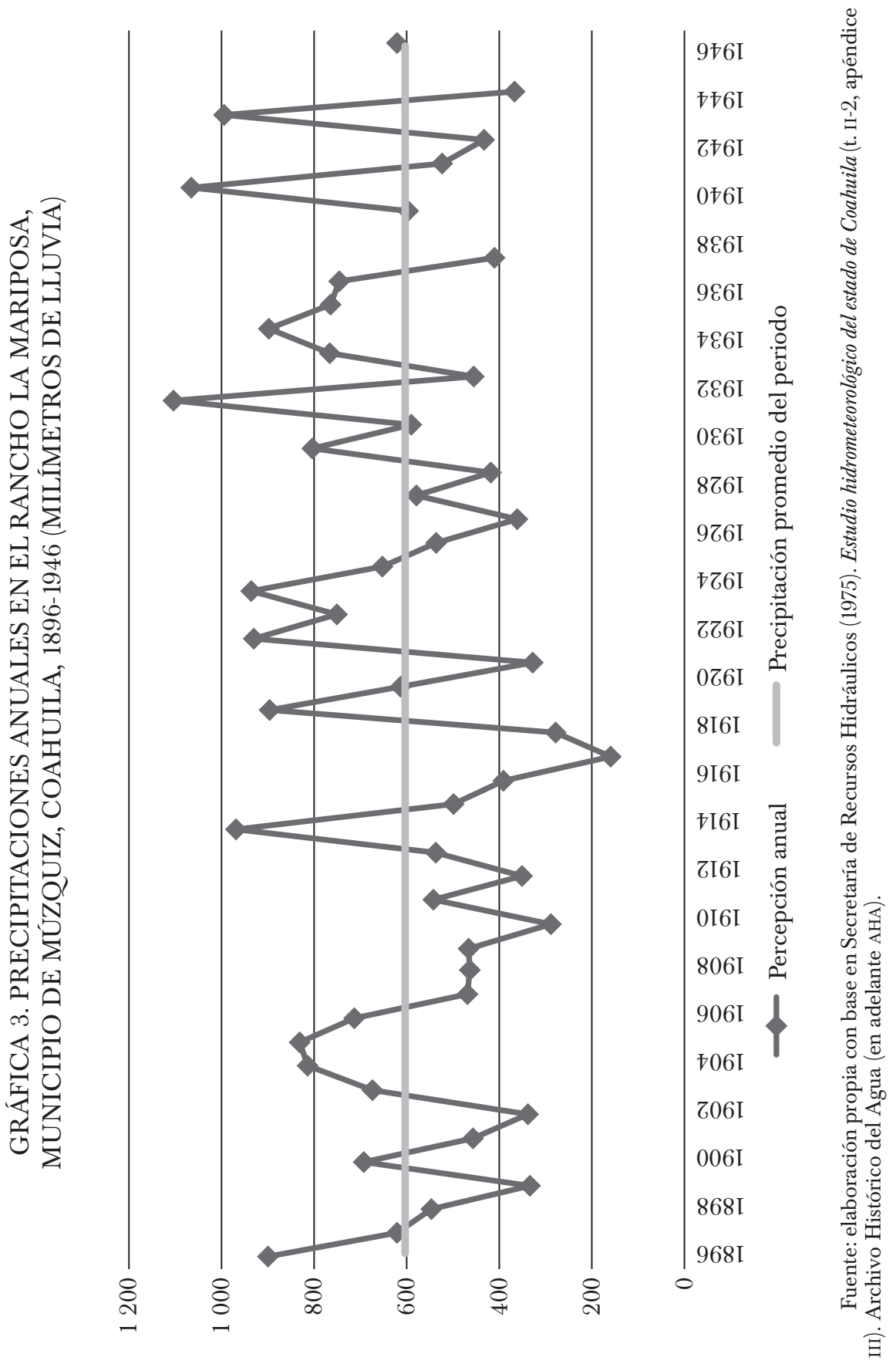


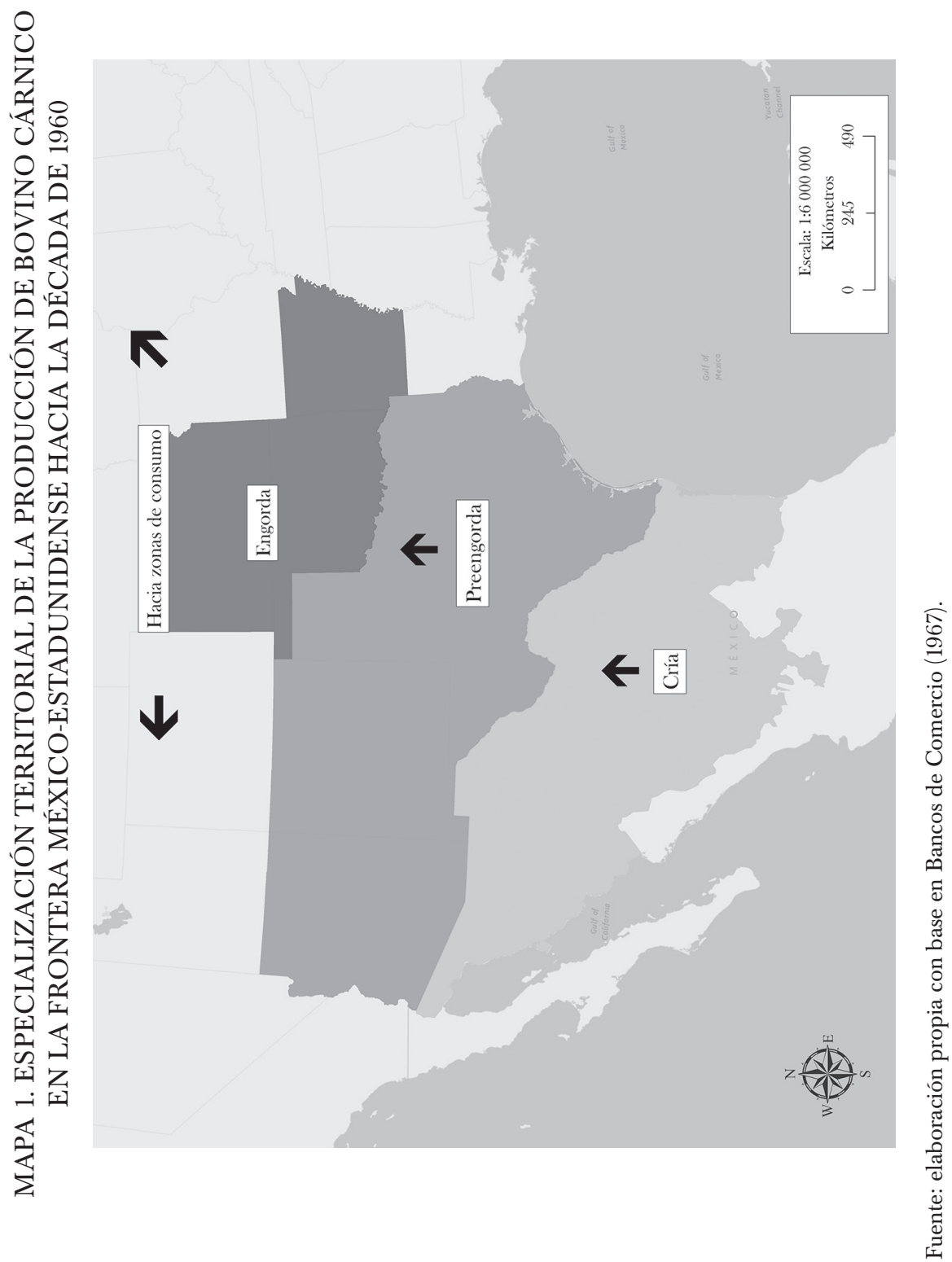




\section{MAPA 2. REGIÓN DE ESTUDIO: NORTE DE COAHUILA}

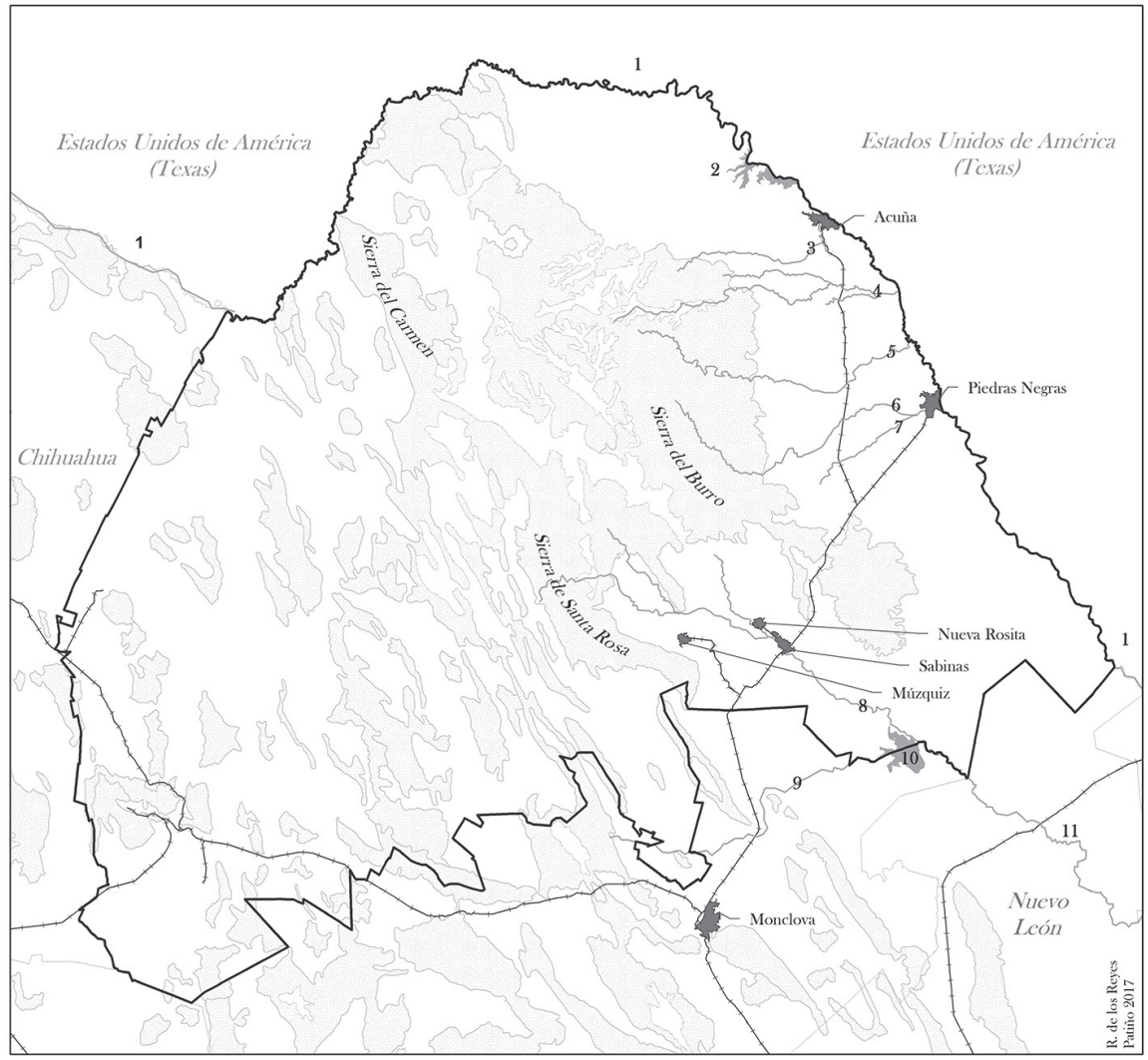

Simbología

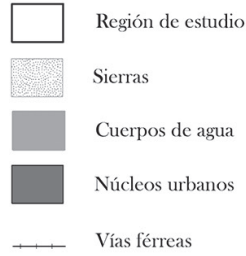

Escala: 1:1,135,000

Kilómetros

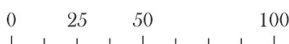

Afluentes y cuerpos de agua

$\begin{array}{ll}\text { 1. Río Bravo } & \text { 7. Río Escondido } \\ \text { 2. Presa de la Amistad } & \text { 8. Río Sabinas }\end{array}$

3. Arroyo Las Vacas 9. Río Nadadores

4. Río San Diego 10. Presa V. Carranza

5. Río San Rodrigo

6. Río San Antonio 11. Río Salado
Estados Unidos de América

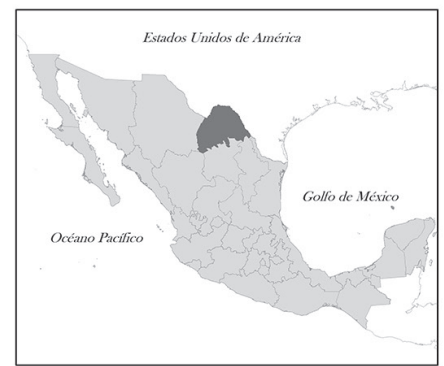

Oćáno Pacifico

Fuente: elaboración propia. 
cebú que había sido importado desde Brasil, aunque no se sabe a ciencia cierta cuál haya sido el causante.

Lo cierto es que de inmediato Estados Unidos cerró la frontera para las importaciones de ganado mexicano, buscando prevenir que la enfermedad llegara a su territorio. En México, se estableció un cordón sanitario que dividió la zona afectada de la zona limpia, es decir, aisló el centro del norte del país. La ganadería norteña, a pesar de estar limpia de fiebre aftosa, resintió este evento al ver cortada su cadena de producción. En los años previos al cierre, se enviaron 500000 cabezas al año a Estados Unidos. Los principales estados exportadores fueron Chihuahua, Sonora y Coahuila, que en conjunto exportaban más de 300000 cabezas.

En esta última entidad, como hemos mostrado, el grado de integración a la economía estadunidense era central. A mediados de siglo, 1200000 hectáreas estaban en manos de extranjeros, principalmente texanos, lo que representaba $21 \%$ de las propiedades censadas y $59 \%$ del valor catastral de las mismas. ${ }^{3}$ Entre las propiedades más importantes resaltaban, por su valor, La Babia, de H. L. Mangum, y por su extensión, la Florida, de George D. Miers. Otro caso relevante por su dimensión política fue el de Dolph Briscoe y Dolph Briscoe Jr., este último gobernador de Texas en la década de 1970.

Dolph Briscoe padre (1890-1954), quien había fincado su fortuna en la ganadería y en la explotación de petróleo en Estados Unidos, quedó en la quiebra tras la crisis de 1929. Entonces apostó por vender sus múltiples propiedades e invirtió en una sola para recuperar su emporio: la propiedad elegida fue la hacienda Margaritas, en Zaragoza, Coahuila, perteneciente a la Rosita Livestock Company. Briscoe conocía bien los ranchos coahuilenses, puesto que por varios años rentó tierras y compró ganado en la entidad. En 1933 estableció su lote de ganado Hereford en el rancho de 90000 hectáreas, y contrató a un ganadero de la región, Robert Spence, para administrarlo. El negocio prosperó rápidamente y al poco tiempo recuperó sus propiedades en Texas, a donde movía las crías nacidas en Coahuila para engordarlas y enviarlas a Kansas City (Briscoe, 2008, pp. 17-20).

En 1947, al enterarse de la irrupción de la epizootia, su socio en Kansas City y vicepresidente del City National Bank en esa ciudad, J. Milton Freeland, mostró su preocupación. En enero de ese año, le escribió a Briscoe diciéndole que la fiebre aftosa podía causar estragos en sus negocios y que, aunque el grueso de sus ingresos no dependiera del ganado mexicano, el virus podía ignorar el cierre de la frontera y expandirse a Texas, donde la

${ }^{3}$ Informes sobre ganadería, 1954. Fondo Secretaría de Gobierno (en adelante SG), c. 14421955, 1. 55. Archivo General del Estado de Coahuila (en adelante AGEC). 
amenaza era mayor. Además, consideraba que las autoridades mexicanas no hacían mucho para combatir la enfermedad, y que no tomaban las medidas necesarias para prevenir su esparcimiento. "Me doy cuenta de que con un solo brote aislado que ocurriera en Texas, nuestras autoridades impondrían regulaciones tan drásticas que podrían reducir sustancialmente el valor del ganado en esta área." Había peligro incluso de que pusieran en cuarentena algunas zonas dentro de Estados Unidos o por lo menos al ganado que había sido importado antes del embargo. "Puedes estar seguro -agregaba el mismo socio- de que usaré todas las influencias que tengo, y, además, haré lo necesario para obtener la influencia de otras personas en este mismo sentido, para tomar fuertes medidas en la situación."

Del lado mexicano, quedaba vulnerable una economía que por su naturaleza no era posible sustentar dentro del territorio nacional. Los pastizales norteños no eran suficientes para alimentar a todo el ganado que se criaba y que encontraba salida en Estados Unidos; y el mercado mexicano, por otro lado, no estaba lo suficientemente desarrollado para absorber toda esa producción. En diciembre de 1947, no obstante, la superabundancia de ganado mexicano encontró una posible salida a través de los planes para establecer plantas enlatadoras de carne. En ese año, el Departamento de Agricultura de Estados Unidos (en adelante USDA, por sus siglas en inglés), por medio de su subsidiaria la Commodity Credit Corporation, realizó estudios e instaló junto con industriales mexicanos una serie de empacadoras de carne y, unos años después, se declaró de interés público la instalación de plantas de tipo inspección federal (Camou, 1998, pp. 166167; Reina, 1958, pp. 278-279).

Aunque los precios pagados por carne enlatada eran apenas la mitad de lo que hubieran recibido anteriormente por exportar el ganado, los ganaderos preferían estos precios a quedar en la ruina. En 1948, el USDA negoció contratos por 73000000 de libras de carne enlatada, y para 1951 Estados Unidos había comprado 218000000 de libras, 150 de las cuales fueron vendidas en Europa. Desde 1949, además, se aceptaba la importación de carne salada. Estos esfuerzos de cooperación binacional, según Machado (1981, p. 75), removieron el estigma de un cierre de fronteras simbolizado por la testarudez estadunidense.

Los ganaderos norteños, mientras canalizaban su producción al mercado interno y a las enlatadoras y empacadoras, esperaban la buena nueva. "Sigo muy esperanzado a que se abra la frontera, [pero] mientras poda-

${ }^{4}$ Cartas de Freeland a Briscoe, 10 y 23 de enero de 1947, Dolph Briscoe Sr. Papers (en adelante DBSP), c. 2.325/U148. Briscoe Center for American History (en adelante BCAH). 
mos vender (el ganado) y hacer un poco de dinero, o simplemente cubrir los gastos, está bien para mí." 5

Briscoe Jr., quien en la posguerra se hizo cargo de todos los negocios de su padre en México, adquiría ganado de criadores locales y lo pastaba en sus predios, esperando con ello mantener los animales mientras se abría la frontera para exportarlos o, en su defecto, los enviaba a la enlatadora local o al mercado de la ciudad de Monterrey.

Todo parecía indicar que para enero de 1952 la frontera sería reabierta, por lo que comenzaron las preparaciones para exportar y, con ello, la especulación. En mayo de 1951, Briscoe y su socio texano, Red Nunley, contrataron la compra de 3000 novillos a 50 dólares por cabeza del rancho La Babia, de los sucesores de Hal Mangum. Los novillos iban a ser recogidos en noviembre de 1952, pero un año antes de esta fecha el contrato quedó cancelado por motivos que desconozco. ${ }^{6}$ Lo cierto es que la cada vez más cercana reanudación de las exportaciones volvió a muchos ganaderos reacios a vender.

La frontera no se abrió en enero, pero parecía inevitable que lo hiciera en algún punto del año. Mientras tanto, Briscoe siguió vendiendo el ganado a la empacadora y sugirió a su socio, Jim Frazier, adquirir novillos de reemplazo y estar preparados para cuando sucediese la apertura. La situación no era tan sencilla. El 1 de mayo de 1952, Frazier le respondió:

A como van las cosas ahora, todos los mexicanos a los que he sondeado son tan buenos apostadores como tú y yo quisiéramos ser. A lo que me refiero es que todos están esperando al 1 de septiembre y no pretenden disponer de su ganado hasta entonces. iHombre! Qué impacto van a llevarse cuando se enteren que un dólar compra casi lo mismo que un peso [...] Parece que han esperado tanto y han construido esa concepción fantástica del "regreso de los buenos tiempos" que mientras tanto permanecen inmutables ante cualquier tipo de estímulo para vender actualmente. Estoy obteniendo sólo unos pocos novillos de algunos poquiteros [...]. ${ }^{7}$

Frazier informó también que cancelarían las fechas que ya tenían programadas para la enlatadora y que por el momento no había que vender nada.

En agosto de 1952, un año antes de la reapertura, México se preparaba para exportar 300000 cabezas de ganado. A pesar del entendible entusiasmo de los mexicanos por exportar, los ganaderos tenían que recordar que dependían de las condiciones del campo estadunidense, que para entonces

\footnotetext{
${ }^{5}$ Carta de Briscoe Jr. a Frazier [socio en Coahuila], 21 de agosto de 1951. DBSP, c. 615. BCAH.

${ }^{6}$ Carta de Denman a Nunley, 8 de noviembre de 1951. DBSP, c. 615. BCAH.

${ }^{7}$ Carta de Frazier a Briscoe, 1 de mayo de 1952. DBSP, c. 615. BCAH.
} 
no eran precisamente las mejores. Si se continuaba extendiendo la sequía en el suroeste de Estados Unidos, iba a ser complicado acomodar ahí tantas cabezas (Machado, 1981, p. 95).

La situación económica de la ganadería al norte del Bravo también era difícil debido a un importante reajuste de precios. En los primeros años de la posguerra, se habían obtenido ganancias extraordinarias dado el aumento de la demanda de carne de res de primera calidad: mientras que en el quinquenio de 1942-1946 el precio promedio de la libra fue de 32.8 centavos, en el de 1947-1951 fue de 67.12 (Breimyer, 1961, p. 47). Sin embargo, ante este incremento, en 1951 la Oficina de Estabilización de Precios de Estados Unidos fijó un tope de precios para las empacadoras y minoristas de carne, lo que, sumado a la sequía que elevó los costos de alimentación del ganado, provocó que grandes cantidades de reses fueran mandadas al mercado y los precios de los novillos comenzaran a caer en 1952 (véase gráfica 4). Dolph Briscoe Jr. (25 de febrero de 1953) calificaba de arribistas (Johnny-come-latelies) a los banqueros y petroleros que, incentivados por los altos precios de la posguerra, especularon en el negocio ganadero; para muchos colegas de Briscoe, estos ganaderos de medio tiempo también habían contribuido a la crisis. En una revista de productores pecuarios, un ganadero analizaba la situación: "Puede ser que la era de los precios inflados haya terminado definitivamente y, si así es el caso, la única salvación de los engordadores es que llueva profusamente y que puedan tener de nuevo reservas alimenticias, para que puedan disminuir los costos de producción acorde a la caída de precios." ${ }^{8}$ Pero no llovía, y la situación era crítica. El mismo autor agregaba que la sequía obligó a dar salida a una cantidad enorme de ganado no siempre de buena calidad, incluyendo el procedente de México y Nueva Zelanda, lo que bajó los precios en demasía.

Con Estados Unidos en una crisis por exceso de oferta, resultaba evidente que las importaciones de ganado mexicano no eran del todo atractivas. Entre 1951 y 1952, la mayoría de las exportaciones coahuilenses fueron de carne procesada; en septiembre de 1952 la frontera fue reabierta y las exportaciones en pie continuaron hasta septiembre de 1953, cuando un nuevo brote de aftosa fue descubierto y la frontera cerrada de nuevo. De las 257000 cabezas exportadas en el año que va de septiembre de 1952 a septiembre de 1953, Coahuila exportó poco más de 37 000, aproximadamente $15 \%$ del total nacional. No fue sino hasta 1955 cuando el problema

${ }^{8}$ R. B. Corbett, febrero de 1953. Producer's problems. American Cattle Producer. The Cattleman's Business Magazine. DBSP, c. 3K413. BCAH. 


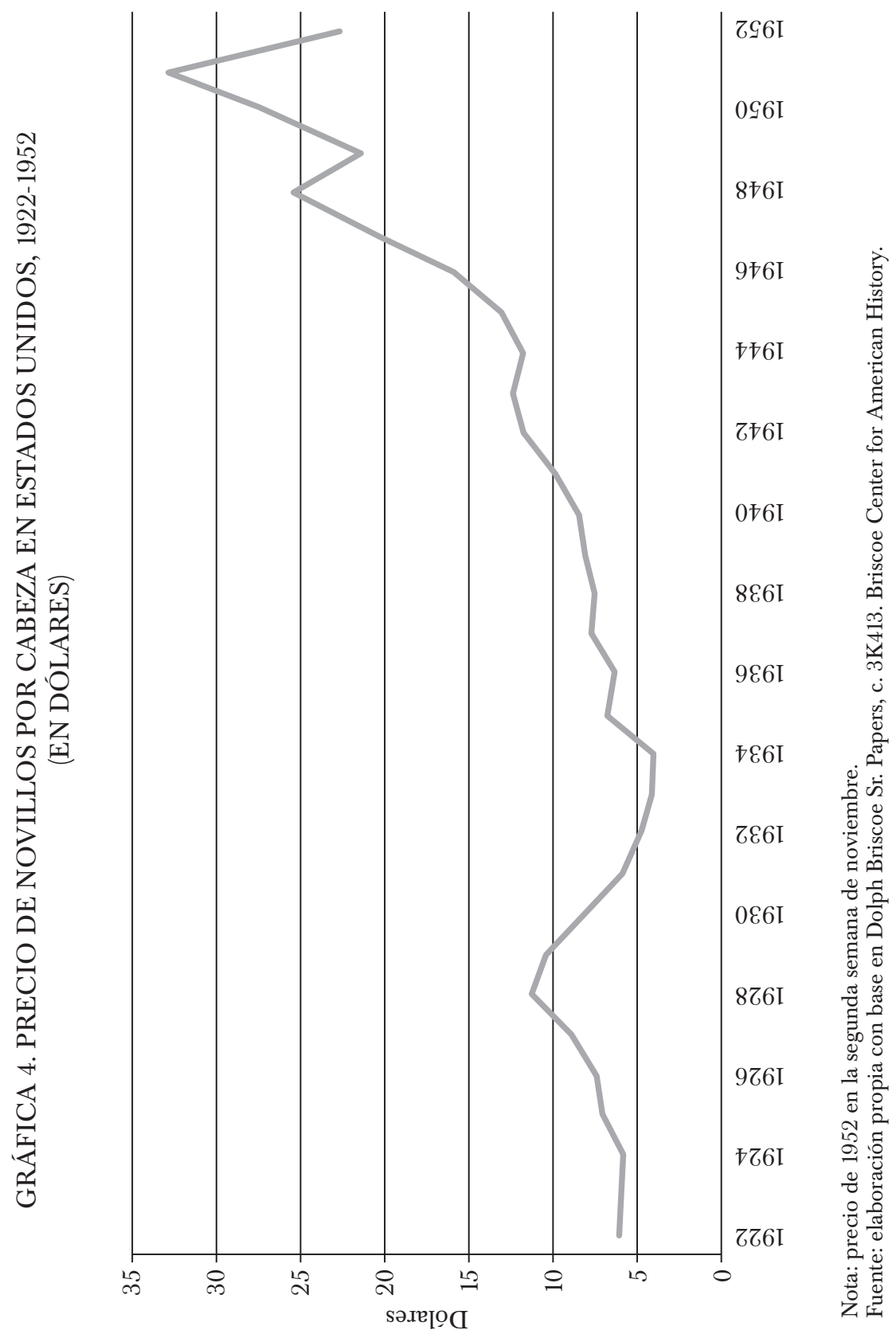


de la aftosa fue superado, y México exportó 313000 cabezas en pie de las cuales $13 \%$ fueron coahuilenses. ${ }^{9}$

Los vaivenes parecían augurar un destino incierto para la exportación. Un estudio del USDA (1957, p. 1) estimaba que México podría exportar cada vez menos ganado debido al aumento de su población y del consumo per cápita. En efecto, entre 1950 y 1960, el ganado sacrificado para el abasto nacional aumentó $90 \%$ y el promedio de consumo per cápita de carne de res pasó de 5.5 a $7.8 \mathrm{~kg}$ anuales por persona. Las dificultades para abastecer el mercado interno, sin embargo, todavía eran muchas.

\section{El mercado interno. Tensiones EN TORnO AL ABASTO DE CARNE DURANTE EL CIERRE DE LA FRONTERA}

El cese de las exportaciones había permitido, en teoría, que hubiera una mayor oferta de carne al interior del país, capaz de abastecer el gran mercado de la capital nacional, así como a mercados emergentes como Monterrey. La situación no era tan simple. En México había muchas bocas que podían absorber la producción de carne del país, pero había muy pocas que pudieran pagarla.

Si las exportaciones a gran escala no se recuperaron hasta después de 1960, ¿qué limitó, durante los años de 1950, la disponibilidad de carne coahuilense para el consumo de la población mexicana? Hay dos posibles respuestas. La primera tiene que ver con las condiciones ambientales, que sumadas a las disposiciones políticas de esa entidad significaron un repliegue de las dinámicas ganaderas, y la segunda, con la política de abasto del mercado nacional que dificultó la integración del ganado norteño al mercado nacional. Exploraré brevemente las dos a continuación.

\section{a) Las condiciones ambientales}

El gran crecimiento ganadero que había tenido la entidad no pudo soportarse con la frontera cerrada y en condiciones de sequía. En 1952, en un informe sobre la situación ganadera del estado, el Departamento de Agricultura y Ganadería de Coahuila explicaba que la falta de precipitaciones en las zonas centro y norte del estado había creado problemas tanto agrícolas como ganaderos, "ocasionando un desequilibrio económico". La producción de forrajes había sido muy deficiente y, señalaba el mismo AGEC.

${ }^{9}$ Cuadros que demuestra la existencia de ganado vacuno en Coahuila, s. f. SG, c. 1442, 1. 55. 
informe, "se puede decir, que para la rama ganadera no existen presas de captación, pues para el sostenimiento de los ganados se cuenta con aguajes y perforaciones". No se practicaban tampoco trabajos de conservación para proteger los suelos contra la erosión y, a pesar de que se inició con la experimentación de pastos, lo inseguro y escaso de las lluvias volvieron riesgosa la empresa. ${ }^{10}$

Con las precipitaciones anuales de Acuña (uno de los municipios más importantes para la ganadería de la entidad), se observa cómo los años de 1952-1953 y 1955-1956 fueron años especialmente secos (véase gráfica 5). El año de 1953 fue crítico, definitivamente malo para la actividad pecuaria coahuilense (a pesar de reabrirse la frontera). El año inició para la ganadería bovina con su máximo histórico de 736000 cabezas, pero quizá ese mismo récord auguraba la crisis: en el transcurso del mismo, hubo un gran número de muertes de ganado atribuidas a la sequía, perdiéndose 162000 cabezas (véase cuadro 1). Este mismo hecho se reflejó en un bajo promedio de ahijadero: mientras en los años previos había sido de $60 \%$, en 1953 cayó hasta 20\%. ${ }^{11}$ Nacieron en ese año menos de la mitad de los animales que habían muerto, sobre todo por la sequía. El año que siguió reportó una disminución de 20\%, es decir, más de 150000 cabezas. Muy probablemente buena parte de esas pérdidas fueron de vacas de vientre, ya que al iniciar el año de 1954 se reportaron alrededor de 80000 cabezas menos. Las vacas de vientre eran el corazón de la actividad de cría, y representaban más de 40\% del valor del ganado en la entidad, ya que en su mayor parte se trataba de ganado Hereford (véase cuadro 2). ${ }^{12}$

Es posible observar otros efectos de la sequía en la movilidad del ganado de la región. Para 1950, el censo agrícola y ganadero de la entidad (México, 1955) reportó casi 500000 cabezas, 65\% de las cuales se encontraban en la región norteña. Los municipios que más habían incrementado su cabaña fueron Ocampo y Sierra Mojada (los más áridos), al pasar de 23000 a 72000 cabezas en ese año. Las inclemencias de la década de 1950 dieron un duro golpe a este crecimiento, ya que durante esos años estos municipios disminuyeron su cabaña en casi 30000 cabezas. En conjunto, seis municipios de la región vieron su hato disminuir en 37000 cabezas,

${ }^{10}$ Departamento de Agricultura y Ganadería de Coahuila, 18 de octubre de 1952. Condiciones agrícolas del Estado, SG, c. 1317-1952, 1. 31. AGEC.

${ }^{11}$ En el sistema ganadero vaca-becerro, como lo es el que se practica en las entidades norteñas del país, el objetivo es que por cada vaca de vientre pueda obtenerse un becerro al año. En este caso, 60 significa que, por cada diez vacas, nacieron seis becerros.

${ }^{12}$ El Hereford es una raza de ganado cárnica proveniente de Inglaterra y es una de las más extendidas del mundo. Desde el siglo XIX tuvo una gran aceptación en el norte de México, dada su rusticidad y su capacidad de recorrer potreros para conseguir alimentos; su cara blanca se ha convertido en un símbolo de la ganadería norteña, como puede observarse en los escudos de algunas de sus uniones ganaderas. 


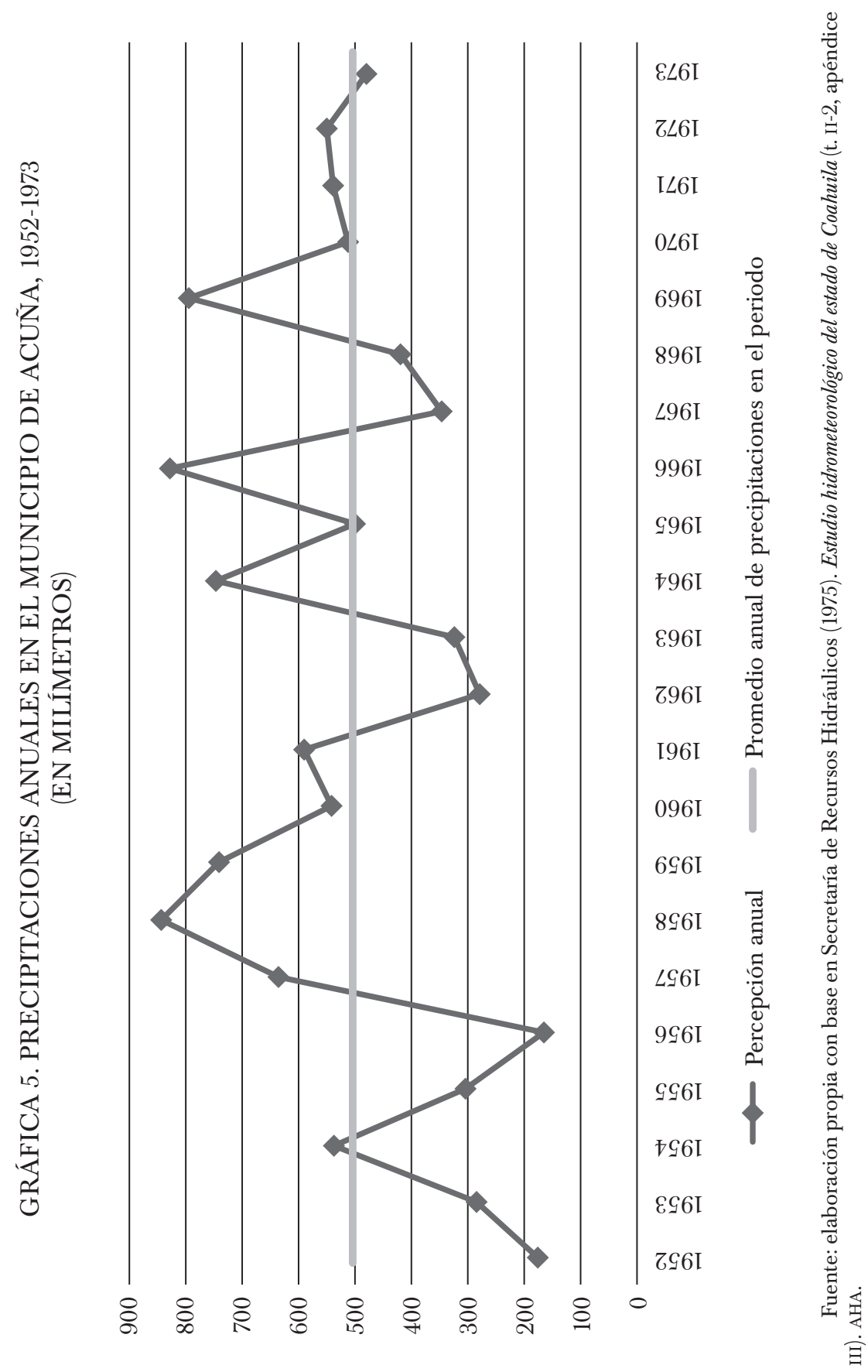




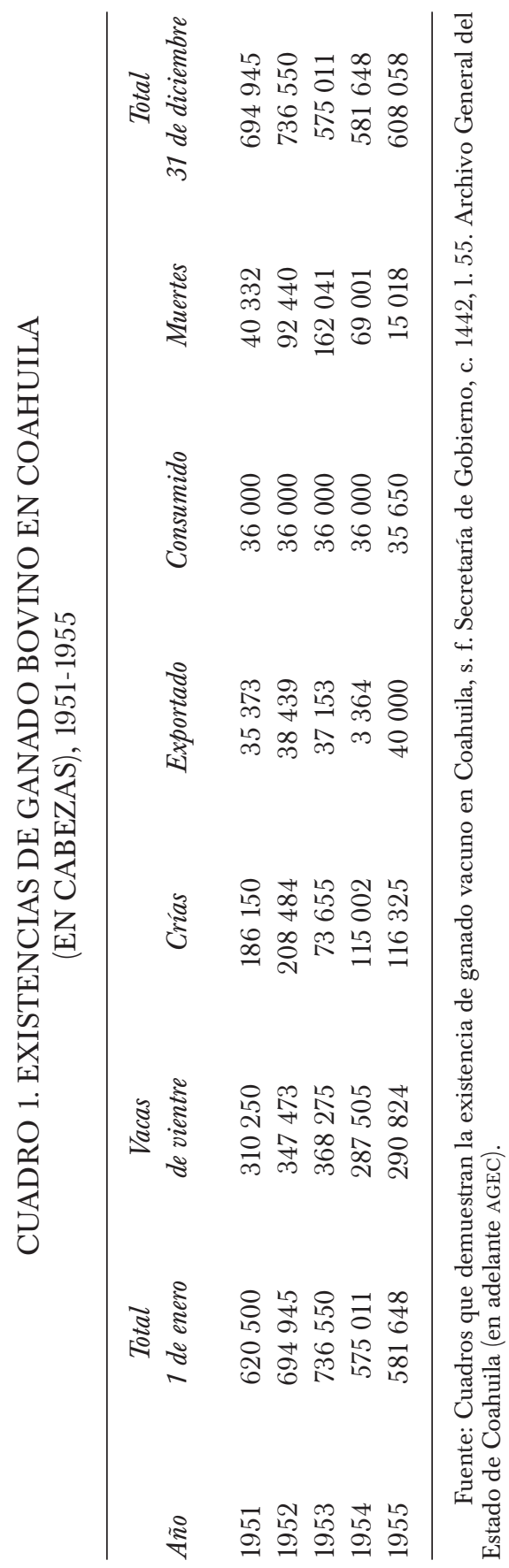




\section{CUADRO 2. VALOR APROXIMADO DEL GANADO VACUNO EN COAHUILA, 1954}

\begin{tabular}{|c|c|c|c|}
\hline Tipo de ganado & Cabezas & $\begin{array}{c}\text { Valor } \\
\text { (miles de pesos) }\end{array}$ & $\begin{array}{c}\text { Porcentaje } \\
\text { del valor total }\end{array}$ \\
\hline \multicolumn{4}{|c|}{ Ganado Hereford para carne } \\
\hline Toros & 44890 & 44890 & 21.08 \\
\hline Vacas vientre & 223164 & 89266 & 41.92 \\
\hline Vaquillas & 89138 & 19285 & 9.06 \\
\hline Novillos & 89138 & 27641 & 12.98 \\
\hline \multicolumn{4}{|c|}{ Lechero fino } \\
\hline Toros & 765 & 1912 & 0.90 \\
\hline Vacas vientre & 6375 & 9562 & 4.49 \\
\hline Vaquillas & 2804 & 1402 & 0.66 \\
\hline Novillos & 2806 & 842 & 0.40 \\
\hline Total & 12750 & 13719 & 6.44 \\
\hline \multicolumn{4}{|c|}{ Ganado corriente } \\
\hline Toros & 12527 & 3064 & 1.44 \\
\hline Vacas vientre & 61284 & 9190 & 4.32 \\
\hline Vaquillas, dos, un año & 24513 & 2942 & 1.38 \\
\hline Novillos, tres, dos, un año & 24514 & 2942 & 1.38 \\
\hline Total & 122568 & 18137 & 8.52 \\
\hline Gran total & 581648 & 212937 & 100 \\
\hline
\end{tabular}

Fuente: valor aproximado del ganado vacuno en el estado de Coahuila, 1954, s. f. Secretaría de Gobierno, c. 1442, 1. 55. AGEC.

mientras que tan sólo en tres municipios, Múzquiz, San Buenaventura y Acuña, este aumentó en casi 100 000, lo que sugiere que la ganadería tendió a concentrarse en espacios de clima más benévolo.

Los ganaderos, acostumbrados a una amplia movilidad transfronteriza, sobre todo en tiempos de sequía, estaban inmersos en graves problemas debido a las restricciones para mover ganado incluso dentro del país. Durante estos años hubo muchas solicitudes al gobernador para sacar los animales a otros ranchos, principalmente a los de Chihuahua, el estado vecino, debido a la escasez de pastos y agua que no cesaba de mermar el ganado. Las respuestas para movilizar miles de cabezas de ganado, sobre todo del noroeste coahuilense hacia Camargo, Chihuahua, no siempre fueron favorables, o exigían el cobro de altos impuestos. No es de 
extrañar, entonces, que en mayo de 1952 se informara al ejecutivo estatal que algunos ganaderos estaban sacrificando hembras de ganado bovino en estado de gestación. ${ }^{13}$

Para colmo de males y, como es frecuente en la región, las lluvias de 1954 (en un contexto de sequía prolongada) provocaron una grave inundación. En junio de ese año, el río Bravo casi desapareció a la ciudad de Piedras Negras y con ella a la enlatadora de carnes de esa ciudad. Para recuperarse, necesitaba una buena inversión, por lo que en 1955 se solicitó un crédito de 1000000 de pesos para realizar las reparaciones necesarias por los desperfectos sufridos. ${ }^{14}$ La sequía no terminó sino hasta 1958, debido a un ciclón que provocó muchas lluvias y, por supuesto, otras inundaciones.

\section{b) Los dilemas del mercado interno}

El mercado externo estuvo vedado por algunos años, y al interior del país la situación tampoco era fácil. La crisis sanitaria provocó el sacrificio de más de 500000 bovinos en el centro del país, reduciendo significativamente la oferta que abastecía la ciudad de México. Sin embargo, tampoco era viable que los ganaderos norteños remitieran su ganado al centro del país, principalmente por los costos del transporte y la poca capacidad de los almacenes refrigerados en el Distrito Federal (Lopes, 2017, pp. 307-312). ${ }^{15}$ La situación creó un alza de precios en la carne y los productos lácteos en las comunidades del centro, lo que, aunado a la desconfianza por ingerir alimentos infectados, disminuyó el consumo; además, los productores también se vieron afectados debido a que no faltaron intermediarios que abusaran del pánico para comprar animales a precios muy bajos y lucrar con ellos (Herrera, 2016, pp. 247-248).

La coyuntura desfavorable propició un esfuerzo entre ambos países por emprender soluciones tanto en materia sanitaria como estrictamente

\footnotetext{
${ }^{13}$ Oficios de Arredondo a Valdez, 3 de septiembre de 1951, y de Narváez al administrador del rastro, 30 de mayo de 1952. SG, c. 1308, 1. 29; c. 1324, respectivamente. AGEC.

${ }^{14}$ Informe sobre ganadería, 1954. SG, c. 1442-1955, 1. 55. AGEC.

${ }^{15} \mathrm{El}$ sistema de distribución del ganado para la ciudad de México funcionaba de la siguiente forma: el ganadero vendía los animales a un negociante, que los llevaba a las zonas de consumo y los vendía a los llamados "introductores", quienes, a su vez, los llevaban al rastro general, donde los "coyotes" (contratistas) la distribuían a los detallistas para que finalmente llegara al consumidor (Secretaría de Economía Nacional, 1934, pp. 41-42). Este sistema dificultó el abastecimiento de la ciudad dada su enorme cantidad de intermediarios: según Lopes (2017), a mediados del siglo XX el sistema funcionaba de forma muy similar a como había operado en el siglo XIX, puesto que los esfuerzos por industrializar la carne habían sido infructuosos, entre otras cosas, debido a la oposición de estos intermediarios amparados en un discurso nacionalista (pp. 296-297).
} 
económicas (Herrera, 2016). Los esfuerzos por industrializar la carne, en ese momento, tenían el propósito de funcionar, por un lado, para aliviar la ganadería norteña, y por otro, para resolver el abasto de la ciudad de México. Sin embargo, había elementos que no convencían por completo a los ganaderos de las entidades norteñas, sobre todo en lo referente a las cuotas de envío a la capital. Las quejas no se hicieron esperar: en Durango, la Unión Ganadera decía que "son muy dignos los habitantes pobres del D. F. [...] pero también [...] los muchísimos campesinos que tienen también sus ganados"; mientras que en Chihuahua solicitaban no cumplir la meta de enviar 15\% de la producción para abastecer a la capital y proponían en cambio enviar las vísceras (véase Lopes, 2017, pp. 313-315).

En Coahuila la situación también parecía complicada. Aunque se trataba de una entidad productora y el sistema de distribución era más simple, los problemas estaban a la orden del día. ${ }^{16}$ En 1954, Gustavo Cárdenas, médico veterinario, afirmaba que debía evitarse "el error gravísimo que se ha cometido en constituirnos en un estado exportador de carne cuando tenemos un promedio de consumo anual de 300 gramos de este alimento por habitante". ${ }^{17}$ Las estadísticas no avalan el dato, y parece más bien que el veterinario exageraba: otro cálculo hecho por él mismo para 1940 indicaba que la disposición anual per cápita de carne de res en el estado era de $8.2 \mathrm{~kg}$; a este último monto, agregaba, se puede sumar $25 \%$ debido al consumo que se hace en ranchos, villas y pueblos que están fuera de control oficial (Cárdenas y Cahero, 1944, pp. 138-139). Para 1950, las estadísticas indican que la disposición habría disminuido a $6.7 \mathrm{~kg}$ en 1950 , y a $5.9 \mathrm{~kg}$ en 1960 (esta última cifra por debajo del promedio nacional) (Machado, 1981, pp. 136-137). En otros términos, podemos decir que mientras la población coahuilense había crecido $30 \%$ en esa última década, la disponibilidad de carne sólo aumentó 10\%. Las cifras de Coahuila no sólo estaban por debajo de las del Distrito Federal, sino de las de sus vecinos de Chihuahua y Nuevo León.

En Coahuila se establecieron dos plantas en la ciudad de Piedras Negras, la Enlatadora de Carnes de la Unión Ganadera Regional de Coahuila (UGRC), que inició operaciones en 1948, y la Empacadora y Refrigeradora de Coahuila, que inició en 1951. Esta última tenía permitido realizar una exportación de $75 \%$ de su producción y remitir $25 \%$ a la ciudad de México. Esta dinámica, mal que bien, consideraba al mercado internacional y al del centro del país, pero no estipulaba nada sobre la demanda local, que

16 La distribución ocurría de forma similar a la ciudad de México, sólo que con menos intermediarios: los ganaderos vendían a los introductores, quienes llevaban al rastro y de ahí se distribuía a los detallistas.

${ }^{17}$ Gustavo Cárdenas, 8 de marzo de 1954. La alimentación del pueblo de Coahuila y la producción animal. SG, c. 1442, 1. 55. AGEC. 
tenía un serio problema de abastecimiento de carne. En 1951, el alcalde de Piedras Negras solicitaba que se dejara una parte de ese 25\% para el consumo de sus habitantes (diez a quince reses diarias) al mismo precio pagado en la ciudad de México. Mientras, la Comisión Proveedora de Ganados para el Distrito Federal solicitaba no sólo la cuota de carne industrializada, sino la exención de impuestos a la importación del ganado vivo que adquiría en la entidad. ${ }^{18}$ Al gobernador de Coahuila, Rafael López Sánchez, parecía afectarle no sólo la merma de ganado, sino la de impuestos.

Puesto que algunos gobiernos estatales tenían facultades para imponer gravámenes al comercio, estas alcabalas neoporfirianas no hacían más que tensar las relaciones tanto con el Distrito Federal como con otras entidades..$^{19}$ Esto se hizo evidente en los conflictos con el segundo mercado en importancia del país, Monterrey. Ricardo Morales, uno de los grandes introductores de ganado en esa ciudad, operaba en Múzquiz, Coahuila, y en 1951 enfrentó serias dificultades para sacar su ganado de esta plaza, debido a que el recaudador de rentas de ese municipio prohibió su salida. No es que estuviera prohibida la salida de ganado de la entidad, sino que el ejecutivo coahuilense había dispuesto que para esto había que aportar $20 \%$ para el consumo de esta entidad a razón de 1.50 pesos el kilogramo en pie, "precio por demás aceptable si se considera que el Distrito Federal obtiene $20 \%$ de nuestro ganado destinado a exportación a un precio de 0.85 pesos el kilo en pie”. El gobernador de Coahuila no tardó en recibir comunicaciones de su homólogo de Nuevo León, Ignacio Morones Prieto, $\mathrm{y}$ de otros funcionarios federales, en el sentido de que facilitara el abasto de Monterrey con ganado coahuilense. El gobernador les respondió que no se disponía de otra carne para consumir en la entidad que la que sus propios ganaderos "pueden ofrecer a nuestro pueblo, cuyas necesidades estoy obligado a atender [...]. El estado de Nuevo León cuenta con ganado suficiente para sus exigencias, sólo que de mala calidad y muy delgado [agregaba el gobernador]. Tratamos de cubrir las necesidades de un estado productor de carne, mi deber es atender las demandas del pueblo coahuilense" ${ }^{20}$ Así, haciendo uso de una retórica de soberanía estatal, estas disposiciones se sumaban a las federales de Estados Unidos y México en el sentido de bloquear el flujo de ganado.

\footnotetext{
${ }^{18}$ Telegramas de Múzquiz a López, 21 de septiembre de 1951, y de Rentería a López, 10 de mayo de 1951. SG, c. 1308, 1. 29. AGEC.

${ }^{19}$ Como ha señalado Aboites (2001), no fue sino hasta 1971 que se suprimieron completamente las alcabalas en México. Algunas entidades, entre ellas Coahuila, se habían resistido a incorporarse al impuesto sobre ingresos mercantiles (pp. 365-366). Esta entidad cobraba gravámenes especiales sobre la cerveza, el trigo y el ganado; en Múzquiz, por ejemplo, se cobraba 1\% sobre la compraventa de trigo y 25 centavos por la inspección de ganado (p. 376).

${ }^{20}$ Telegrama de López a Martínez, 14 de julio de 1951. SG, c. 1308, 1. 29. AGEC.
} 
Ciertamente, la demanda efectiva de la población local era pequeña, por lo que no representaba un mercado atractivo para absorber la producción. Por ello, al mismo tiempo que la Unión Ganadera aceptaba la petición del gobernador de establecer centros de distribución de carne en los distintos pueblos, esta buscaba también otros mercados para la salida de los excedentes, celebrando un contrato con la International Packers Commercial Division Limited de Chicago, considerando que su planta enlatadora iniciaría trabajos pronto y aprovecharían para vender algo de su producto a la gente de esa ciudad. ${ }^{21}$ Como señala Lopes (2017), aunque no faltaron las voces contrarias a la integración estadunidense desde el centro del país, la realidad era que no había incentivos para reorientar la producción al centro (p. 315).

El problema entonces no era en realidad la falta de ganado, sino que los costos de producción no coincidían con la demanda interna, lo que creaba un desfase que para los ganaderos se volvía rentable sólo si se aprovechaban los precios de Estados Unidos. En un estudio sobre los costos de la producción de ganado para abasto en Coahuila, Gustavo Cárdenas, médico veterinario, decía:

Se necesita estar dotado de un espíritu heroico y un temperamento a prueba de sinsabores y desilusiones para ser ganadero en el estado de Coahuila ya que en la explotación de este tipo de ganado se obtienen rendimientos que en ocasiones ni siquiera compensan los esfuerzos desarrollados. Es una de las razones por las que los criadores del estado prefieren vender su ganado en los mercados norteamericanos donde les pagan precios más altos en dólares. Esto ha provocado un alza en el precio local del kilo de carne. ${ }^{22}$

Además de contribuir un poco a la mitología del ganadero domeñando a la naturaleza, lo que explica el médico Cárdenas es la correlación entre las exportaciones y el alza de precios: conforme aumentaba la inflación en México, la capacidad de compra de los consumidores en relación con los productos cárnicos era cada vez menor en el mercado interno y mayor el incentivo para trasladar la producción hacia afuera. Lo interesante en ese estudio es que, después de hacer un análisis detallado de todos los costos que implica la producción de ganado (impuestos incluidos), llega a la conclusión que la utilidad neta para los productores es apenas de $2 \%$ anual sobre la inversión, mientras el gobierno percibe poco más de $16 \%$ por impuestos y, el banco, $9 \%$ de interés sobre el capital prestado. Esta situación

\footnotetext{
${ }^{21}$ Oficio de la UGRC a Cepeda, 6 de enero de 1954. SG, c. 1442, 1. 55. AGEC.

${ }^{22}$ Gustavo Cárdenas, 8 de marzo de 1954. Cálculo de costos de producción del ganado bovino para abasto. SG, c. 1442, 1. 55. AGEC.
} 
afectaba profundamente a los criadores, pero no así a los revendedores, comisionistas, agentes de compras, etc., encargados de adquirir a bajos precios animales que directa o indirectamente eran llevados a los centros de abasto tanto del país como de Estados Unidos. Estos en cambio aprovechaban la situación crítica del productor, haciéndole anticipos monetarios para obligarlo a vender a bajos precios. El excesivo intermediarismo no sólo para el mercado nacional, sino también para el de exportación, significó un lastre para muchos productores y fue sin duda uno de los problemas más agravantes para el desarrollo regional, que se vería afectado en los siguientes años.

\section{EL AUGE DE LA GANADERÍA MEXICANA Y LA DEBACLE DE LA GANADERÍA DEL NORTE COAHUILENSE}

La década de 1950 parece haber marcado profundamente la ganadería coahuilense que, durante el próximo decenio, no viviría de la misma forma el auge ganadero del resto del país. En esa década, el promedio de crecimiento anual de la ganadería bovina nacional fue de $2.9 \%$, crecimiento que se dio sobre todo en la región tropical, aunque también en el norte, donde el promedio de crecimiento estuvo ligeramente por encima de la media. En el norte de Coahuila, sin embargo, la situación fue distinta. En esa década su hato se mantuvo prácticamente estancado, al pasar de 392000 a 374000 cabezas, representando una disminución de $0.46 \%$ anual (véase cuadro 3).

\section{a) El estancamiento}

La palabra que se encuentra frecuentemente en los informes de la época es estancamiento. Un reporte de los Bancos de Comercio (1967) sobre la economía coahuilense en 1967, dedica un amplio apartado a atender el problema de la ganadería, donde, se dice, "el ganadero vive una gran incertidumbre en lo que respecta a la propiedad de sus tierras, una intranquilidad que se ha reflejado palpablemente en el desempeño de la actividad pecuaria en general" (p. 29).

Si bien los estados norteños no habían crecido a tasas tan elevadas, sí estaban mejorando la calidad del ganado. En Coahuila, poco más de 30\% del ganado bovino encontrado a finales de la década de 1960 era ganado de registro, predominantemente Hereford, aunque también Aberdeen Angus, Charolais, Cebú y cruzas de estos. Lo inquietante respecto a este porcentaje de ganado fino, decían, era que no había aumentado en los últimos 
CUADRO 3. CRECIMIENTO PROMEDIO ANUAL DE LA GANADERÍA BOVINA, 1950-1981 (PORCENTAJES)

1950-1960

2.82

1.80

2.96
1960-1970

$-0.46$

2.98

2.90
1970-1981

1.15

$-0.40$

0.65

Fuente: elaboración propia con base en México $(1955,1965,1975)$ e Instituto Nacional de Estadística, Geografía e Informática (1990). Dado que el censo de 1981 sólo incluye totales por entidad, estimé los valores para la región norte de Coahuila tomando en cuenta la participación de la región en el total estatal de 1970 .

años: "Más aún, según los propios ganaderos, el hecho de que la tercera parte sea ganado fino es más bien fruto de la inercia y no de un panorama atractivo. Lo cierto es que la creación de los pies de cría exigió varios años de esfuerzo continuado, que, de interrumpirse, representaría echar abajo todo lo conseguido. Significaría perder la labor de muchos años" (Bancos de Comercio, 1967, p. 29).

El censo agrícola y ganadero de 1960 (México, 1965) coincidía con que la tercera parte del ganado coahuilense era considerado fino, pero el de 1970 no fue tan benévolo con esta afirmación. Según este último, sólo lo era 14\%, y si aislamos a la región del norte de Coahuila los resultados indican que se pasó de 33\% de ganado fino en 1950 a solamente 13\% en 1970. Sólo tres municipios, Múzquiz, Ocampo y Zaragoza, habían perdido en conjunto más de 55000 cabezas, más de la mitad de las que existían en 1950 .

El problema fundamental al que aludían los ganaderos era la incertidumbre respecto a la propiedad de la tierra. Sencillamente, decían, "el ganadero no disfruta de la seguridad necesaria para que dedique todo su empeño a esta actividad. Hay temor de afectaciones; de disminuciones de la propiedad. En consecuencia, la gente no invierte o invierte poco.” Esto no sólo frenó las inversiones tendentes a aumentar la productividad de las explotaciones pecuarias, sino que fue agotando los pastizales naturales por pastoreo excesivo, lo que a su vez obligó a los productores a comprar cada vez más alimentos balanceados, como harinolinas, cascarillas y melazas, para nivelar la alimentación de sus animales, aumentando, lógicamente, el costo de producción (Bancos de Comercio, 1967, pp. 30-31).

Aunque es cierto que muchos ganaderos temían expropiaciones de tierras, también lo es que los incentivos económicos del mercado estaduni- 
dense, así como las obligaciones políticas del mercado mexicano, llevaron a la sobreexplotación de los predios coahuilenses. Las tensiones por atender esta doble conexión siguieron, como mostraré en el siguiente apartado, sobre todo conforme la población mexicana creció de forma sostenida hacia la década de 1970.

\section{b) Las exportaciones y el mercado interno}

La producción de bovinos en Coahuila para finales de la década de 1960 se estimaba en 140000 cabezas anuales (lo que indica que no varió mucho desde la década anterior). De ellas, aproximadamente 50000 se exportaban, 50000 se consumían en la entidad, 25000 eran enviadas a mercados del interior (principalmente Monterrey), y 15000 a la ciudad de México.

Los años de 1966 a 1968, debido a las lluvias abundantes y a los precios, que fueron muy atractivos para la exportación, permitieron que en ese último año México se convirtiera en el primer exportador mundial de ganado en pie con 712000 cabezas, seguido por Canadá, con 353000 cabezas (Comisión Económica para América Latina, 1972, p. 6). A pesar de este auge, Coahuila apenas exportaba $7 \%$ de esta cuota, la mitad de la participación porcentual que ostentaba hasta la década pasada.

Por otro lado, respecto a la carne industrializada, dicha entidad contaba con una cuota de sacrificio para exportación de 5000 cabezas en las dos plantas tipo inspección federal con las que contaba. El problema con ellas era que, de nuevo, se encontraban en una disyuntiva entre el mercado interno y las exportaciones, debido a que el gobierno interrumpió estas últimas aduciendo que mientras el centro del país no tuviese carne suficiente, no se debía exportar carne industrializada. Los ganaderos coahuilenses criticaban esta medida debido a que, afirmaban, se ignoraba el hecho de que las empacadoras operaban con carne magra, que sería rechazada por el público (Bancos de Comercio, 1967, p. 34).

Tanto en tiempos donde se prohibía la exportación como en tiempos donde alcanzaba su máximo histórico, encontramos la constante tensión entre esta y el mercado interno, sobre todo en una época donde primó una política de mercados protegidos. La gran demanda de la ciudad de México acentuaba este hecho, ya que para este momento existía la disposición de que todo exportador de ganado en pie remitiera a dicha ciudad el equivalente a 20\% de sus exportaciones. Los ganaderos acataban esta exigencia, remitiendo frecuentemente animales criollos, viejos y flacos, comprados a campesinos de bajos recursos, lo que les permitía no distraerse de su producción de becerros ni usar sus vaquillas. 
Coahuila había estado enviando hasta $20 \%$ más del que correspondía. En 1966, por ejemplo, se enviaron 15000 cabezas que representaban 30\% de su exportación. El problema no era de hecho la cantidad que debía remitirse. Las quejas en este sentido se apoyaban en las condiciones del abasto: la mitad de la cuota debía ser aportada en tiempos de escasez y la mitad en tiempos de abundancia. El problema era que en la ciudad de México se pagaban los mismos precios en ambas temporadas, mientras que solamente las entidades exportadoras estaban obligadas a enviar ganado al Distrito Federal en tiempo de escasez. Esta época se refiere normalmente al segundo trimestre del año, en tiempo de sequía, cuando el ganado pierde peso y a ningún productor le conviene vender. En el traslado, además, el ganado perdía de 12 a $17 \%$ de su peso. Las condiciones no eran favorables en ningún sentido, y de hecho los estados que no estaban obligados a vender detenían sus envíos a la capital durante esta época.

Los mercados del interior del país operaban de forma diferente. Tenían precios diferenciados dependiendo de la época. Monterrey pagaba más que la capital, además de que para los coahuilenses los costos de transporte eran bastante menores. El propio mercado coahuilense pagaba precios más atractivos. En opinión de los ganaderos, hubo una época más sana, cuando se quitó el monopolio del rastro de Ferrería y se autorizó la libre introducción de carne al Distrito Federal. El incentivo del precio que ofrecían las cadenas de supermercados y comerciantes en general hizo factible y costeable la engorda, pero con el regreso del monopolio y la escasez de frigoríficos, todo se volvía más complicado (Bancos de Comercio, 1967, pp. 34-36).

Las exportaciones, sin embargo, resultaban aún bastante rentables y hacían ver estos inconvenientes como males menores. Entre 1971 y 1980 , Coahuila exportó más de 600000 cabezas. Los rendimientos fueron bastante buenos y permitieron la consolidación de algunos negocios, gracias a los precios que alcanzó el ganado en Estados Unidos. En 1965, el kilogramo de becerro en pie se cotizaba en .46 dólares en Texas; en 1970 llegó a .73; en 1973 llegó a 1.27 y al cerrar la década estaba en 1.94 dólares por kilo. Hasta 1967, siete estados se distribuían las cuotas de exportación concedidas por el gobierno federal: Chihuahua, Sonora, Durango, Coahuila, Zacatecas, Nuevo León y Tamaulipas. Un año después se sumó Aguascalientes, algunos municipios de Jalisco y otros de San Luis Potosí en 1974. En el periodo de 1971-1980, cuatro estados concentraron 90\% de las más de 5500000 cabezas exportadas (véase gráfica 6).

Para esta época, según Sanderson (1986, p. 136), la industria exportadora mexicana se dividía en dos sectores: uno de alta tecnología, semiintensivo, destinado a la exportación de novillos de engorda y dominado por Sonora y Chihuahua, y otro más extensivo, proveedor de carne magra 


\section{GRÁFICA 6. PARTICIPACIÓN DE LAS ENTIDADES EN LAS EXPORTACIONES DE BECERROS, 1971-1980}

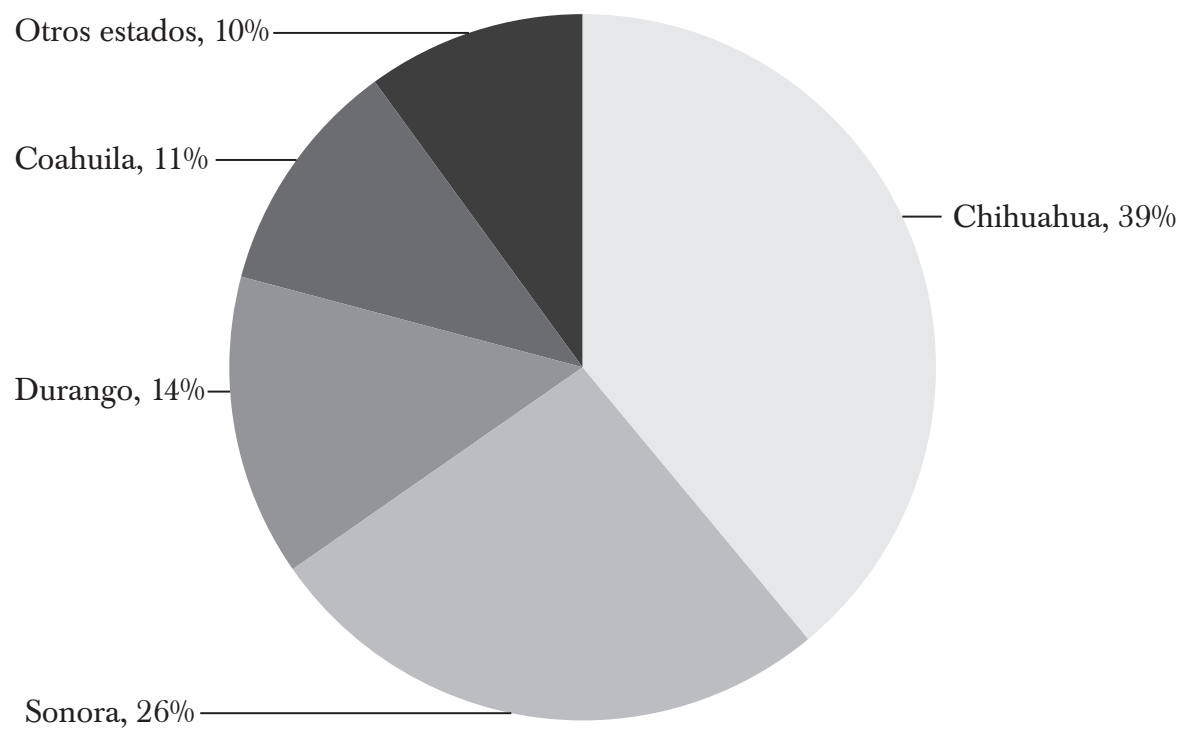

Fuente: elaboración propia con base en Meza (2008, p. 65).

tanto para exportaciones como para consumo interno, donde Coahuila y Chihuahua eran los ejemplos característicos. Esto es congruente con lo que mencionamos anteriormente respecto a la ganadería coahuilense, en cuanto a que la reducción de su ganado fino pudo disminuir su inserción en la demanda de novillos finos de engorda, aunque se mantuvo en el mercado de exportación dado el aumento en la demanda estadunidense de carne magra para comida procesada y congelada.

En este sentido, ambos sectores ganaderos se insertaron en el auge de las exportaciones tanto de ganado en pie como de carne deshuesada de los rastros tipo inspección federal, que llegaron a su máximo punto en el periodo de 1970-1974, para iniciar luego una notable decadencia. Esta coincidió, por un lado, con una baja considerable en el consumo de carne de res en Estados Unidos (que a la fecha no se ha detenido), y con un aumento del consumo mexicano. Este último prácticamente se duplicó al pasar de 2000000 de cabezas anuales en el quinquenio 1960-1964 a cerrar 
el periodo de 1975-1979 con casi 4000000 de cabezas. Este aumento en el consumo, junto con una crisis financiera que impactó a la ganadería a partir de 1976, provocaría que al finalizar los setenta, la ganadería dejara de participar con divisas para el financiamiento del desarrollo nacional (Meza, 2008, pp. 61-67).

Algunos autores vieron en esta doble conexión la incapacidad de satisfacer plenamente las demandas alimenticias de la población mexicana. En 1980, argumenta Sanderson (1986, pp. 139-141), una quinta parte de la cabaña nacional era exportada o sacrificada en México anualmente. Ello drenó la capacidad reproductiva de los hatos, y en el caso norteño significó una pérdida de superioridad genética y reproductiva. El mismo autor agrega que los intentos del Estado mexicano por reorientar la cadena productiva hacia el interior del país, como lo expresó el plan del Sistema Alimentario Mexicano, no tuvieron el éxito deseado, dada la falta de integración de la industria mexicana de la carne, sobre todo en lo relativo a la engorda, transportación y comercialización.

La ganadería del norte de Coahuila, como la de una buena parte del resto del país, tuvo serios problemas para adaptarse en los años subsiguientes. A principios de la década de 1980, la actividad comenzó a disminuir sus ganancias y entró en un proceso de crisis que se agudizó a finales de esos años. La apertura comercial instrumentada por el estado trajo una descapitalización del sector agrícola, y posteriormente lo colocó en una posición de desventaja respecto al de Estados Unidos, que comenzó a inundar de carne barata el mercado mexicano, en el que la carne coahuilense tampoco pudo competir (Vidaurrázaga y Cortez, 2000, pp. 216-218).

\section{CONCLUSIONES}

La ganadería del norte de Coahuila, una región en la frontera mexicana con Estados Unidos, se insertó en el mercado internacional de carne desde finales del siglo XIX. Producto de un desbordamiento de la economía texana, su inserción fue tanto comercial como territorial. La comercial se dio a través de la exportación de ganado en pie para ser engordado al norte del Bravo, mientras que la territorial ocurrió debido a la adquisición de tierras por parte de extranjeros, quienes volvieron al norte mexicano una extensión de sus propiedades en Texas.

Dicha extensión obedeció a las dinámicas espaciales de la actividad ganadera, que, sustentadas en un ecosistema frágil, dieron mucha movilidad a los animales para no sobrecargar los pastos. En este artículo, argumenté que a raíz de la crisis sanitaria que cerró la frontera al intercambio de ganado, y en un contexto ambiental desfavorable, hubo un repliegue 
parcial de dichas dinámicas, no sólo al interior del país sino dentro de la entidad.

El repliegue fue producto, por un lado, del mencionado cierre, pero también de las disposiciones políticas que buscaron atender la demanda de los grandes centros del país, así como de la población local. Las restricciones impuestas por el gobierno estatal obstaculizaron la salida de ganado no sólo al centro sino a estados vecinos, lo que se tradujo en una enorme mortalidad que afectó la capacidad productiva de la cabaña coahuilense.

Esta, con una reducción de sus existencias y de la calidad de las mismas, respondió durante las décadas de 1960 y 1970 a los incentivos económicos del mercado internacional, así como a las demandas políticas del país, cuya población iba en aumento. Sin embargo, su crecimiento fue constantemente por debajo del resto de las entidades norteñas, y operó en un clima de incertidumbre que no estimuló las inversiones. Su inserción en el mercado de carne magra tanto para Estados Unidos como para México revitalizó el mercado en esas décadas, pero en la de 1980 fue incapaz de responder a los retos de la liberación de mercados.

Queda pendiente el estudio de otras regiones fronterizas para entender mejor la reestructuración del sector ganadero en la segunda mitad del siglo XX. Estos estudios deben atender los factores políticos, económicos y ambientales de ambos lados de la frontera para entender mejor el proceso productivo. Por otra parte, queda pendiente en este trabajo y en posteriores ahondar en otras fases del proceso económico, principalmente la comercialización y el consumo, mismas que pueden dar otras luces a la explicación.

\section{LISTA DE REFERENCIAS}

Aвоites, L. (2001). Alcabalas posporfirianas. Modernización tributaria y soberanía estatal. Historia Mexicana, 51(2), 363-393.

Aвогтеs, L. (2013). El norte entre algodones. Población, trabajo agrícola y optimismo en México, 1930-1970. México: El Colegio de México.

AnZALdúa (1987). Borderlands/La Frontera: The new mestiza. San Francisco: Spinsters/ Aunt Lute.

Bancos de Comercio (1967). La economía del estado de Coahuila. México: Colección de Estudios Económicos Regionales.

Breimyer, H. (1961). Demand and prices for meat: Factors influencing their historical development. Washington: United States Department of Agriculture.

Briscoe, D. JR. (25 de febrero de 1953). The Houston Chronicle [recorte de periódico].

Briscoe, D. (2008). Dolph Briscoe: My life in Texas ranching and politics. Austin: Texas University Press. 
CAmou, E. (1998). De rancheros, poquiteros, orejanos y criollos. Los productores ganaderos de Sonora y el mercado internacional. México: El Colegio de Michoacán/Centro de Investigación en Alimentación y Desarrollo, A. C.

Cárdenas, G. y Cahero, M. (1944). Regiones ganaderas del estado de Coahuila. México: Secretaría de Agricultura y Fomento.

Cerutti, M. y GonzÁlez, M. (comps.) (1993). Frontera e historia económica. México: Instituto Mora/Universidad Autónoma Metropolitana.

COMisión ECONÓMICA PARA AMÉRICA LATINA (1972). Análisis y perspectivas de la industria de la carne de ganado bovino en México. México: Autor.

EwIng, S. (1995). The ranch. A modern history of the North American cattle industry. Missoula: Mountain Press Publishing Company.

Herrera, O. (2016). Carácter transnacional de las epizootias. La fiebre aftosa en México y la disputa por el control sanitario y el mercado del ganado entre Estados Unidos y América Latina en los años de la posguerra mundial. En Mercados en común: estudios sobre conexiones transnacionales, negocios y diplomacia en las Américas (siglos XIX y XX) (pp. 227-259). Ciudad de México: El Colegio de México.

History of the cattlemen of Texas: A brief resumé of the live stock industry of the Southwest and a biographical sketch of many of the important characters whose lives are interwoven therein. (1991). Austin: Texas State Historical Association.

Instituto Nacional de Estadística, Geografía E Informática (1990). VI Censos agrícola-ganadero y ejidal, 1981: resumen general, resultados muestrales a nivel nacional y por entidad federativa. México: Autor.

Katz, F. (1998). La guerra secreta en México: Europa, Estados Unidos y la revolución mexicana. México: Era.

Lopes, M. (2003). Circuitos comerciales de la ganadería en el norte de México, algunas líneas de investigación. América Latina en la Historia Económica, 10(2), 99-111. DOI: 10.18232/alhe.v10i2.328

Lopes, M. (2008). Revolución y ganadería en el norte de México. Historia Mexicana, 57(3), 863-910.

LOPES, M. (2016). Carne para "las masas hambrientas". Interconexiones del comercio de ganado vacuno en el Atlántico Norte, 1884-1914. En M. Lopes y M. ZuletA (coords. y eds.), Mercados en común: estudios sobre conexiones transnacionales, negocios y diplomacia en las Américas (siglos XIX y XX) (pp. 79-117). Ciudad de México: El Colegio de México.

Lopes, M. (2017). Escasez, epizootia y experimentos sindicales. El abasto de carne en la capital federal mexicana, 1929-1955. En E. QUIROZ (coord.), Integración y desintegración del espacio económico mexicano: mercado interno y abastecimiento de las carnes desde la colonia al siglo XX (pp. 295-330). México: Instituto Mora.

Lopes, M. y RiguzzI, P. (2012). Borders, trade, and politics: Exchange between the United States and Mexican cattle industries, 1870-1947. Hispanic American Historical Review, 92(4), 603-635. DOI: 10.1215/00182168-1727827 
Lopes, M. y Zuleta, M. (coords. y eds.) (2016). Introducción. En Mercados en común: estudios sobre conexiones transnacionales, negocios y diplomacia en las Américas (siglos XIX y XX) (pp. 11-42). Ciudad de México: El Colegio de México.

Machado, M. (1981). The North Mexican cattle industry, 1910-1975: Ideology, conflict, and change. College Station: Texas A\&M University Press.

McKellar, M. (1994). Life on a Mexican ranche. Bethlehem: Lehigh University Press.

MéXICO (1955). Tercer censo agrícola, ganadero y ejidal, 1950: Coahuila. México: Talleres Gráficos de la Nación.

MÉXICO. Dirección General de Estadística (1965). IV Censo agrícola, ganadero y ejidal, 1960: Coahuila. México: Autor.

MéXICO. Dirección General de Estadística (1975). V Censo agrícola-ganadero y ejidal, 1970: Coahuila. México: Autor.

Meza, H. (2008). Auge y crisis de la ganadería mexicana (1940-2005) (Tesis de maestría). Universidad Nacional Autónoma de México, México.

Mora-Torres, J. (2001). The making of Mexican border: The state, capitalism, and society in Nuevo Leon, 1848-1910. Austin: The University of Texas Press.

PÉrez, E. (1991). La modernización ganadera en el marco internacional. Su impacto en América Latina y México. En E. CAMOU (coord.), Potreros, vegas y mahuechis. Sociedad y ganadería en la sierra sonorense (pp. 439-472). Sonora: Gobierno del Estado de Sonora.

Reina, A. (1958). La industria de la carne en México. México: s. e.

SANDERSON, S. (1986). The transformation of Mexican agriculture: International structure and the politics of rural change. Princeton: Princeton University.

SECRETARÍA de ECONOmía NACIONAL (1934). La industria de la carne: abasto de ganado, distribución y consumo. México: Talleres Gráficos de la Nación.

United States Department of Agriculture [usda] (1940-1987). Census of Agriculture Historical Archive. Recuperado de http://agcensus.mannlib.cornell.edu/AgCensus/ homepage.do

United States Department of Agriculture. Foreign Agricultural Service [USDA] (1957). Mexico's livestock and meat industry. Washington: Autor.

VidAurRáZAGa, F. y CORTEZ, A. (2000). El tratado de libre comercio y la ganadería bovina de carne de la región fronteriza de Coahuila. Estudios Fronterizos, 1(1), 189-221.

WALsh, C. (2008). Building the borderlands. A transnational history of irrigated cotton along the Mexico-Texas border. College Station: Texas A\&M University Press.

\section{OTRAS FUENTES}

\section{Bibliografía}

PILcher, J. (2006). The sausage rebellion: Public health, private enterprise, and meat in México City, 1890-1917. Albuquerque: University of New Mexico Press. 


\section{Archivos}

AGEC Archivo General del Estado de Coahuila, México.

AHA Archivo Histórico del Agua, Ciudad de México, México.

BCAH Briscoe Center for American History, Universidad de Texas, Austin, Estados Unidos. 